\title{
Deaggregation of Probabilistic Seismic Hazard and Construction of Pseudo-Exact Conditional Spectrum for China
}

Kun Ji ( $\boldsymbol{\sigma}_{\text {jikun@iem.ac.cn ) }}$

China Earthquake Administration Institute of Engineering Mechanics https://orcid.org/0000-00030314-5216

\section{Ruizhi Wen}

China Earthquake Administration Institute of Engineering Mechanics

\section{Yefei Ren}

China Earthquake Administration Institute of Engineering Mechanics

\section{Weiyi Wang}

China Earthquake Administration Institute of Engineering Mechanics

\section{Lansheng Chen}

China Earthquake Administration Institute of Engineering Mechanics

\section{Research Article}

Keywords: conditional spectrum (CS), spectral acceleration (Sa)

Posted Date: June 2nd, 2021

DOl: https://doi.org/10.21203/rs.3.rs-567089/v1

License: (c) (i) This work is licensed under a Creative Commons Attribution 4.0 International License. Read Full License 


\section{Deaggregation of Probabilistic Seismic Hazard and Construction}

2 of Pseudo-Exact Conditional Spectrum for China

3 Authors: Kun Ji, Ruizhi Wen*, Yefei Ren, Weiyi Wang, Lansheng Chen

4 Affiliations: Key Laboratory of Earthquake Engineering and Engineering Vibration

5 Institute of Engineering Mechanics, China Earthquake Administration

6

\section{Authors' Address and Email:}

Associate Professor Kun Ji

Mailing Address: No. 29 Xuefu Road Harbin, Heilongjiang 150080, People's Republic of China

Email: jikun@iem.ac.cn

Professor Yefei Ren

Mailing Address: No. 29 Xuefu Road Harbin, Heilongjiang 150080, People's Republic of China

Email: renyefei@iem.net.cn

Miss Weiyi Wang

Mailing Address: No. 29 Xuefu Road Harbin, Heilongjiang 150080, People's Republic of China

Email: wywang1996@163.com

Mr. Lansheng Chen

Mailing Address: No. 29 Xuefu Road Harbin, Heilongjiang 150080, People's Republic of China

Email: 1130788614@qq.com

\section{* Corresponding author:}

Professor Ruizhi Wen

Key Laboratory of Earthquake Engineering and Engineering Vibration Institute of Engineering Mechanics, China Earthquake Administration No. 29 Xuefu Road Harbin, Heilongiiang 150080, People's Republic of China Tel: +86-0451-86652617

Fax: +86-0451-86664755

Email: ruizhi@iem.ac.cn 


\section{Abstract}

38 For mainland China, the primary obstacle in conditional spectrum (CS) based ground motion selection work is that the corresponding seismic hazard deaggregation results were not 40 released for the China national standard GB 18306- 2015 "Seismic Ground Motion Parameter 41 Zonation Map”, which refers to the fifth-generation seismic hazard map. Therefore, this study 42 firstly constructed a probabilistic seismic hazard map for mainland China using the three level 43 seismicity source models as applied to produce the fifth-generation seismic hazard map. The 44 derived peak ground acceleration (PGA) values in our seismic hazard map were basically consistent with the fifth-generation seismic hazard map for most of the 34 principal Chinese cities considered. Then, three-dimensional deaggregation scheme was performed for PGA and 5\%-damped spectral acceleration (Sa) corresponding to mean return periods of 475 and 2475 years. Based on the magnitude-longitude-latitude deaggregation results of three example cities: Xichang, Kunming, and Xi'an, approximate and pseudo-exact conditional spectrum were 50 established with/without considering multiple casual earthquakes and possible strike directions 51 of the potential source areas. The mean pseudo-exact CS lies between the results of approximate CS using long and short axis GMMs. The conditional standard deviation of pseudo-exact CS is approximately 1.1 to 1.5 times larger than the approximate CS for the periods away from the conditional period. For three example cities, hazard consistency of the spectral accelerations of the ground motion realizations matching target distribution of pseudoexact CS and geometric mean approximate CS were evaluated and validated. Moreover, for the 34 studied cities, we tabulated the uniform hazard curve and deaggregation results for PGA and $\mathrm{Sa}$ values $(0.2,0.3,0.5,0.7,1.0,1.5$, and 2.0s) at MRPs of 475 and 2475 years. (https://github.com/JIKUN1990/China-Seismic-Hazard-Deaggregation-34cities) 


\section{Introduction}

62 The China Earthquake Administration (CEA, 2015) developed the fifth-generation national standard "Seismic Ground Motion Parameter Zonation Map" (GB 18306-2015), which has also become part of the current national seismic design code of buildings GB 50011-2010 (MHURC, 2016). The fifth-generation seismic hazard map includes a horizontal peak ground acceleration (PGA) map, characteristic period (i.e., the second corner period, $T_{\mathrm{g}}$, of the response spectra) map, and site amplification adjustment coefficients considering various site classes (Gao, 2015). As established by the National Research Council (NRC, 1988), seismic hazard deaggregation (or disaggregation) is an inseparable part of probabilistic seismic hazard analysis (PSHA), which help separate the contributions to the mean annual rate of exceedance of a specific ground motion value at a target site attributable to scenarios of magnitude (M), source-to-site distance $(\mathrm{R})$, and the ground motion error term $(\varepsilon)$. However, the hazard deaggregation results for mainland China, or at least the principal cities, have not yet been officially released or published.

The unavailability of this deaggregation information is an obstacle that cannot be ignored in many engineering applications or studies. For example, hazard deaggregation could provide essential information regarding the selection of appropriate ground motion records for testing the adequacy of the design of new structures or the seismic response of existing ones. Without clear earthquake scenario information (e.g., magnitude and distance), the design seismic group and design intensity levels defined in the current Chinese seismic code (GB 50011-2010) are too ambiguous to match corresponding real ground motion recordings (Wen et al., 2018). Additionally, many hazard-consistent target spectrum or distribution, such as the conditional spectrum, CS (Baker and Cornell, 2005; 2006; Baker, 2011) or generalized conditional intensity measurements (GCIM) method (Bradley, 2010; 2012), cannot be constructed and applied for realistic engineering projects in China owing to the lack of deaggregation information. To solve the problem, Lv et al(2017) used the stochastic finite fault method to obtain the ground motion prediction models, and accomplished the PSHA, deaggregation work for Xi'an city region in China. Authors (Ji et al., 2018) developed an empirical M-R- $\varepsilon$ seismic hazard deaggregation procedure according to the PSHA results of the local seismic safety evaluation of engineering projects in China. Relying on these results, the approximate CS was built according to the deaggregation results. However, the procedure was cumbersome for engineering application and the hazard level were not consistent with the current fifth- 
generation seismic hazard map because the utilized GMM and seismicity models are different. Besides that, CMS or CS are not easy to be implemented in practice considering that the seismicity information given in seismic safety evaluation report is usually not intact and not accessible to public.

In this study, we first developed a seismic hazard map using the three-level seismicity models applied to produce the fifth-generation national Seismic Ground Motion Parameter Zonation Map. The seismic hazard results for 34 principal cities in China were then validated by comparison with the hazard levels released in the fifth-generation zonation map. Then, the hazard results were disaggregated to identify the dominant earthquake scenarios that contribute to the resulting ground motion hazard of the 34 target cities. The cities of Xichang, Kunming, and Xi'an were selected as representative examples for analysis of the corresponding deaggregation results based on the joint $\mathrm{M}-\mathrm{R}-\varepsilon$ distributions and longitude-latitude distributions. Based on the deaggregation results, approximate and pseudo-exact CS were established. Finally, hazard consistency of the spectral accelerations matching target CS were verified at different conditional periods.

\section{China Seismic Hazard Map}

\subsection{Adopted CPSHA procedure}

Before discussing hazard deaggregation work in relation to China, it is important to introduce the China PSHA (CPSHA) scheme. The CPSHA scheme, which is modified based on classical PSHA techniques, was applied in development of the fifth-generation national Seismic Ground Motion Parameter Zonation Map and adopted for development of the hazard map used in this study.

As described in Gao (2015), the seismicity model of the CPSHA scheme is based on three levels of seismicity source areas: the seismic province (Level 1), background seismicity zone (Level 2), and tectonic potential source areas (Level 3), as illustrated in Fig. 1(a). First, the seismic province is divided based on the seismic zones that reflect the overall statistical seismic activity of the region. An upper magnitude limit $\left(M_{\mathrm{uz}}\right)$, the $b$ value of the Gutenberg-Richter (G-R) distribution (Anderson and Luco, 1983), and the annual rate of occurrence of earthquakes of $\geq M 4\left(v_{4}\right)$ are then defined for the seismic province. The background seismicity zone is then divided within the seismic province according to the background tectonic differences among different parts of the seismic zones. It is done to illustrate the features of 
124 small-moderate earthquake seismicity in the different tectonic backgrounds. The background 125 upper magnitude limit $\left(M_{\mathrm{b}}\right)$ needs to be given for this level. Then, the tectonic potential source 126 area is extracted from the background seismic zone to represent the local tectonic features and 127 seismic congregation belt (or zone). Usually, the value of $M_{\mathrm{b}}$ is not smaller than that in the 128 background seismicity zone. In background seismicity zones, only earthquakes of small129 moderate magnitude could occur, whereas tectonic potential source areas include all 130 earthquake events that do not exceed the upper magnitude limit. The locations of the 29 seismic 131 provinces and 77 background seismicity zones of mainland China (Gao, 2015) used in our 132 study are illustrated in Fig. 1(b) with corresponding number labels. The values of $M_{\mathrm{uz}}, b, v_{4}$, 133 and $M_{\mathrm{b}}$ are also listed in Table 1.

134 The seismicity model of the CPSHA method follows three basic assumptions:

135 (1) Magnitude distribution satisfies the truncated G-R relation in the seismic province.

136 (2) Earthquake occurrence in the seismic province satisfies the Poisson distribution.

143 calculated as follows:

$$
P\left(m_{j}\right)=\frac{2 \exp \left(-\beta\left(m_{j}-M_{0}\right)\right)}{1-\exp \left[-\left(M_{u z}-M_{0}\right)\right]} \operatorname{gsh}\left(\frac{\beta}{2} \Delta m\right),
$$

144 where $\beta=b \ln 10$, and $M_{0}$ and $M_{\mathrm{uz}}$ are the lower and upper magnitude limits, respectively, in 145 the seismic province.

146 According to assumption (2), the annual rate of occurrence of earthquake events for which 147 $M \geq M_{0}$ satisfies the Poisson distribution:

$$
P(n)=\frac{\left(v_{0}\right)^{n} \exp \left(-v_{0}\right)}{n !}
$$

Bender (1986) proposed that the assumption of homogeneous source zones is inaccurate and suggested using the normal distribution to assign seismicity around a single point, which 
could make seismicity vary smoothly across source zone boundaries. According to assumption

151 (3), the probability of $m_{j}$ earthquake events occurring in a seismic province, $P\left(m_{j}\right)$, is also not 152 distributed uniformly. In CPSHA, the heterogeneous nature of seismicity in the source area is 153 reflected by the magnitude spatial distribution function, $f_{l, m_{j}}$, which refers to the probability 154 of $m_{j}$ earthquake events occurring in the $i$-th source area. The summation of $f_{l, m_{j}}$ in one seismic 155 province should equal unity. Then, the $m_{j}$ earthquake occurrence probability of a random point $156(x, y)$ in the $i$-th source area $P\left((x, y) \mid m_{j}\right)$ could be defined as Eq. (3), where $A_{i}$ is the area of 157 the $i$-th potential source:

$$
P\left((x, y) \mid m_{j}\right)=f_{l, m_{j}} \cdot \frac{1}{A_{i}} .
$$

Given that $m_{j}$ earthquakes occur randomly in the $i$-th potential source area of the $k$-th seismic province, the probability of an intensity measure (IM) of >im at the target site is defined 160 as follows:

$$
P(I M>i m)_{k}=\sum_{j=1}^{N m} \iint P(m j)_{k} \cdot P\left((x, y) \mid m_{j}\right)_{k} \cdot P\left(I M>i m \mid\left(m_{j},(x, y)\right) d x d y\right.
$$

161 where $P\left(I M>\operatorname{im} \mid\left(m_{j},(x, y)\right)\right.$ is calculated using the GMMs. Finally, the CPSHA annual 162 exceedance probability of $I M \geq i m$ at the target site can be derived as follows:

$$
\begin{aligned}
& P(I M>i m)= \\
& 1-\exp \left[-\sum_{k=1}^{N z} \sum_{j=1}^{N m} \sum_{i=1}^{N s} \iint P\left(I M>\operatorname{im} \mid\left(m_{j},(x, y)\right) \cdot \frac{v_{k} f_{l, m_{j}}}{A_{i}} \cdot \frac{2 \exp \left(-\beta\left(M_{j}-M_{0}\right)\right)}{1-\exp \left[-\left(M_{u z}-M_{0}\right)\right]} \operatorname{gsh}\left(\frac{\beta}{2} \Delta m\right) d x d y\right]\right.
\end{aligned}
$$

163 In the fifth-generation Seismic Ground Motion Parameter Zonation Map, the GMMs 164 developed by Yu et al. (2013) (hereafter, YLX13) were used with consideration of the 165 differences in seismic activity between different regions of China. Four sets of coefficients 166 were derived for four regions by YLX13: (1) Tibet region: the Tibetan Plateau; (2) Xinjiang 167 region: the Xinjiang region except the Tarim Basin; (3) Eastern active region: the seismically 168 active regions in eastern China, the North China Block, and regions along the southeast coast 169 of China; and (4) Stable regions: including the South China Block in southeast China, northeast 170 China, the Erdos Basin, and the Tarim Basin. These four regions are represented by different 171 colors in Fig. 1(b). The YLX13 GMMs were developed for $M_{\mathrm{s}}$ in the range of 5-8, and an 172 epicenter distance $\left(R_{\text {epi }}\right)$ in the range of 0-200 km. They were developed for sites with values 
173 of $V_{\mathrm{S} 30} \geq 500 \mathrm{~m} / \mathrm{s}$, which are defined as rock sites. By multiplying the site amplification factors

174 as described in Gao (2015), the ground motions from YLX13 regarding Chinese Class II soil 175 sites were predicted and used to construct the final fifth Seismic Ground Motion Parameter 176 Zonation Map.

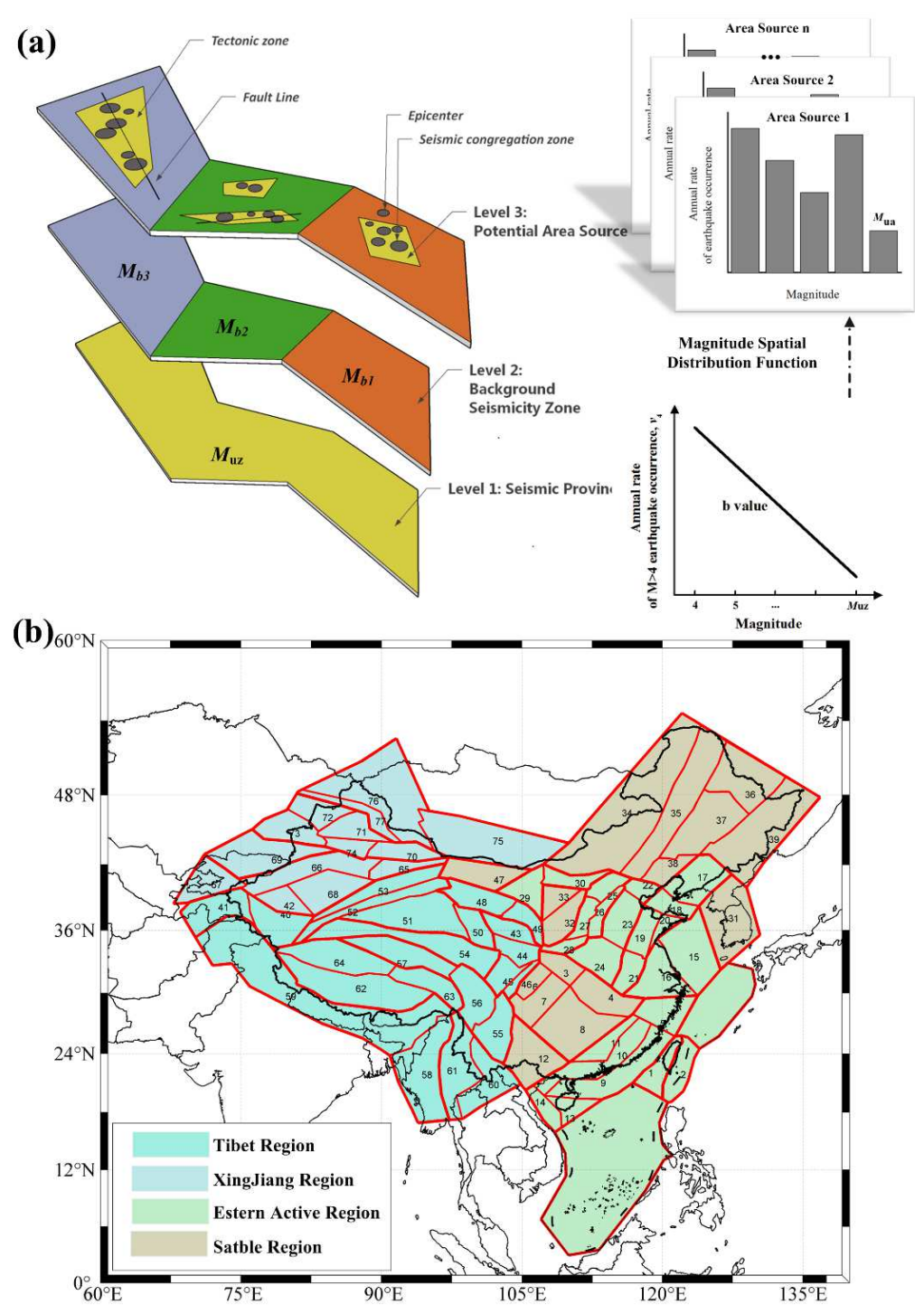

Fig. 1 (a) Tri-level seismic source model including the seismic province, background seismicity zone, and tectonic features zone (left). The seismicity of the seismic province has nonuniform distribution and is assigned between different potential source areas using the magnitude spatial function, while the distribution of seismicity is uniform within the potential source areas (right). (b) Spatial distribution of the 29 seismic provinces and 77 background seismicity zones. The different colors represent the four GMMs applied in four different regions. 
Table 1 Seismicity parameters for the seismic provinces and background seismicity zones in China

179

\begin{tabular}{|c|c|c|c|c|c|c|c|c|c|c|c|c|c|c|c|c|c|}
\hline ID & $\begin{array}{l}\text { Code } \\
\text { Num }\end{array}$ & $\mathrm{Mb}$ & $\mathrm{Mu}$ & $\mathrm{b}$ & $v_{4}$ & ID & $\begin{array}{l}\text { Code } \\
\text { Num }\end{array}$ & $\mathrm{Mb}$ & $\mathrm{Mu}$ & $\mathrm{b}$ & $v_{4}$ & ID & $\begin{array}{l}\text { Code } \\
\text { Num }\end{array}$ & $\mathrm{Mb}$ & $\mathrm{Mu}$ & $\mathrm{b}$ & $v_{4}$ \\
\hline 1 & I1 & 6 & 7.5 & 0.9 & 22 & 29 & III5-a & 5.5 & \multirow{2}{*}{8} & \multirow{2}{*}{0.9} & \multirow{2}{*}{4.5} & 58 & V4-1a & 6.5 & \multirow{2}{*}{9} & \multirow{2}{*}{0.85} & \multirow{2}{*}{83} \\
\hline 2 & $\mathrm{I} 2$ & 6.5 & 8 & 0.92 & 107 & 30 & III5-b & 5.5 & & & & 59 & $\mathrm{~V} 4-1 \mathrm{~b}$ & 7 & & & \\
\hline 3 & II1-a & 5 & \multirow{6}{*}{7} & \multirow{6}{*}{1.2} & \multirow{6}{*}{3.2} & 31 & III6-a & 6 & 7 & 1.05 & 2 & 60 & $\mathrm{~V} 4-2 \mathrm{a}$ & 6 & \multirow{2}{*}{8} & \multirow{2}{*}{0.77} & \multirow{2}{*}{20} \\
\hline 4 & III-b & 5 & & & & 32 & III7-a & 5.5 & \multirow{2}{*}{6.5} & \multirow{2}{*}{1.2} & \multirow{2}{*}{1} & 61 & $\mathrm{~V} 4-2 \mathrm{~b}$ & 6 & & & \\
\hline 5 & II1-c & 5 & & & & 33 & III7-b & 5 & & & & 62 & V4-3a & 6.5 & \multirow{3}{*}{8.5} & \multirow{3}{*}{0.81} & \multirow{3}{*}{25} \\
\hline 6 & II1-d & 5 & & & & 34 & IV-a & 5 & \multirow{6}{*}{7.5} & \multirow{6}{*}{1} & \multirow{6}{*}{5} & 63 & V4-3b & 6.5 & & & \\
\hline 7 & II1-e & 5 & & & & 35 & IV-b & 5 & & & & 64 & V4-3c & 6.5 & & & \\
\hline 8 & III-f & 5 & & & & 36 & IV-c & 5 & & & & 65 & VI-1a & 6 & \multirow{4}{*}{8.5} & & \\
\hline 9 & II2-a & 5.5 & \multirow{6}{*}{8} & \multirow{6}{*}{0.87} & \multirow{6}{*}{5.6} & 37 & IV-d & 5 & & & & 66 & VI-1b & 6.5 & & 11 & 4 \\
\hline 10 & II2-b & 5 & & & & 38 & IV-e & 5 & & & & 67 & VI-1c & 6.5 & & 1.1 & 44 \\
\hline 11 & II2-c & 5 & & & & 39 & IV-f & 5 & & & & 68 & VI-1d & 5.5 & & & \\
\hline 12 & II2-d & 5 & & & & 40 & V1-a & 6.5 & & & & 69 & VI-2a & 6.5 & 8.5 & 0.8 & 7 \\
\hline 13 & II2-e & 5 & & & & 41 & V1-b & 7 & 8 & 0.92 & 50 & 70 & VI-3a & 6 & & & \\
\hline 14 & II2-f & 5.5 & & & & 42 & V1-c & 6 & & & & 71 & VI-3b & 5.5 & & & \\
\hline 15 & III1-a & 6 & 75 & 085 & 3 & 43 & V2-1a & 6 & & & & 72 & VI-3c & 6 & 8 & 0.83 & 9 \\
\hline 16 & III1-b & 5.5 & 1.0 & 0.03 & 3 & 44 & $\mathrm{~V} 2-1 \mathrm{~b}$ & 6.5 & 8 & 071 & 52 & 73 & VI-3d & 6 & & & \\
\hline 17 & III2-a & 5.5 & & & & 45 & V2-1c & 6.5 & 0 & 0.11 & 3.2 & 74 & VI-3e & 6 & & & \\
\hline 18 & III2-b & 5.5 & & & & 46 & V2-1d & 6 & & & & 75 & VI-4a & 6.5 & & & \\
\hline 19 & III2-c & 5.5 & 8.5 & 0.85 & 4 & 47 & V2-2 & 5.5 & & & & 76 & VI-4b & 6.5 & 8.5 & 0.75 & 7 \\
\hline 20 & III2-d & 5 & & & & 48 & $\mathrm{~V} 2-2 \mathrm{a}$ & 6 & 8.5 & 0.75 & 6.4 & 77 & VI-4c & 6 & & & \\
\hline 21 & III2-e & 5.5 & & & & 49 & $\mathrm{~V} 2-2 \mathrm{~b}$ & 6 & & & & & VI-5 & & 7 & 1.2 & 1.6 \\
\hline 22 & III3-a & 5.5 & & & & 50 & $\mathrm{~V} 2-3 \mathrm{a}$ & 6 & & & & & VII & & 7.5 & 1.05 & 6 \\
\hline 23 & III3-b & 5.5 & 8 & 0.86 & 4.6 & 51 & $\mathrm{~V} 2-3 \mathrm{~b}$ & 6 & 85 & 084 & 12 & & VIII & & 7 & 1.05 & 6 \\
\hline 24 & III3-c & 5.5 & & & & 52 & $\mathrm{~V} 2-3 \mathrm{c}$ & 6 & $0 . J$ & 0.04 & 12 & & & & & & \\
\hline 25 & III4-a & 5.5 & & & & 53 & V2-3d & 5.5 & & & & & & & & & \\
\hline 26 & III4-b & 5.5 & 85 & 078 & 25 & 54 & V3-1a & 6.5 & 8.5 & 0.75 & 6.5 & & & & & & \\
\hline 27 & III4-c & 5.5 & $0 . J$ & 0.10 & 2.5 & 55 & V3-2a & 6 & & & & & & & & & \\
\hline 28 & III4-d & 5.5 & & & & 56 & V3-2b & 6.5 & 8 & 0.85 & 32 & & & & & & \\
\hline & & & & & & 57 & V3-2c & 6.5 & & & & & & & & & \\
\hline
\end{tabular}




\subsection{Comparison with the fifth-generation seismic zonation map}

181 The YLX13 GMMs for four regions of China were used and applied along the direction of

182 fault strike (long axis) and perpendicular to fault strike (short axis). For each potential source 183 area, the specific fault strike direction was defined according to the tectonic fault characteristics.

184 For faults with two possible strike directions, the probability for each direction was defined 185 and implemented in the logic trees. Overall, 29 source provinces, 77 background seismicity 186 zones, and 1199 tectonic potential source areas were implemented in computation of the map 187 of the seismic hazard of mainland China. The corresponding magnitude spatial distribution 188 function was implemented to compute the corresponding magnitude-frequency relationship 189 for each source area.

190 To validate our calculated results and ensure that they resembled the current national 191 standard, we compared our results with the fifth-generation seismic zonation map. The PGA 192 values defined in the fifth-generation seismic hazard map were set as the larger PGA value of 193 the 475- and 2475-year results divided by a factor of 1.9. This factor is the average value of 194 the 475- and 2475-year results (Gao, 2015). In the fifth-generation zonation map, there are six 195 defined PGA bins: $0.05,0.10,0.15,0.20,0.30$, and $0.40 \mathrm{~g}$, representing the range of PGA 196 values illustrated in Fig. 2(c) using error bars. The PGA values in the fifth-generation seismic 197 hazard map refer to the Chinese Class II site category, which approximately covers the C and 198 D boundary of the National Earthquake Hazards Reduction Program (Lu and Zhao, 2007; Ji et al., 2017). We also computed the larger of the 475- and 2475-year MRP PGA values divided

200 by a factor of 1.9 for rock sites, which we then converted into Class II site results using the site 201 amplification coefficients provided by the national standard (CEA, 2015). The comparison 202 results for the 34 studied cities in different provinces of China are illustrated in Fig. 2(c). Of 203 these cities, 26 are within the range of the PGA bins of the fifth-generation zonation map, and 204 the remaining 8 cities are close to the upper and lower limits of the range. In the fifth-generation 205 zonation map, the PGA values of some cities or regions need to be adjusted by local 206 government owing to economic level or other political reasons that are not discussed further in 207 this paper. 
(a)

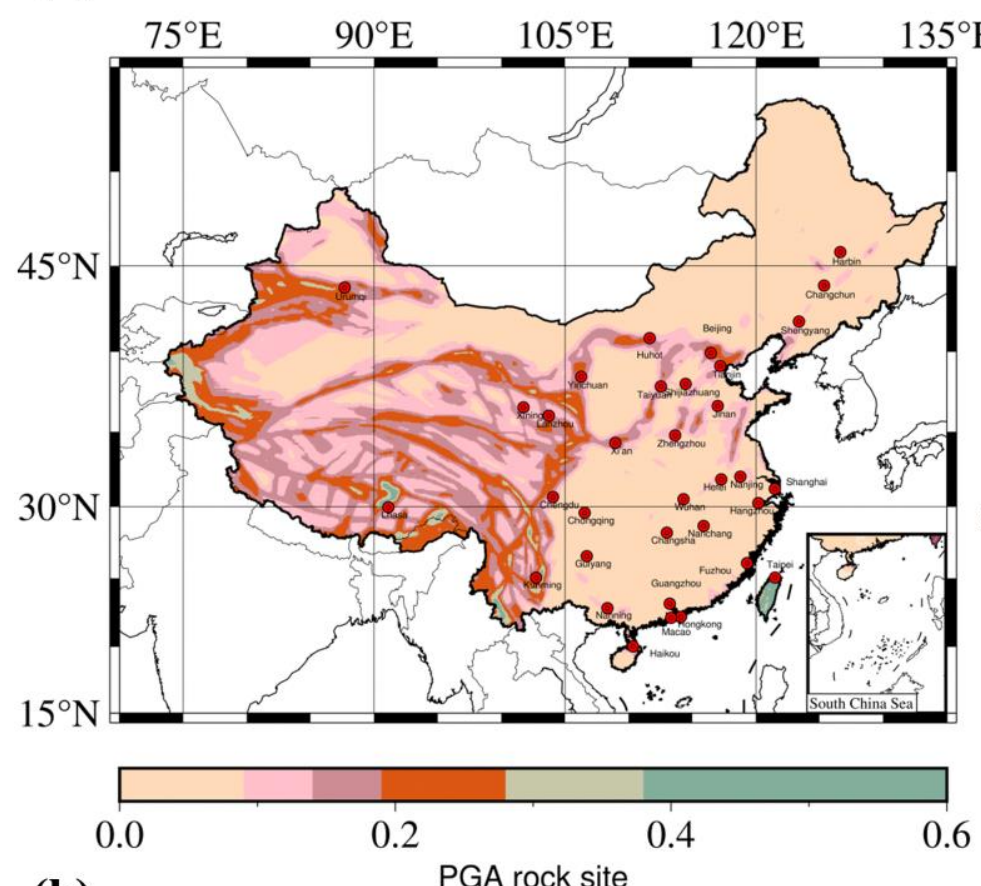

$135^{\circ} \mathrm{E}$
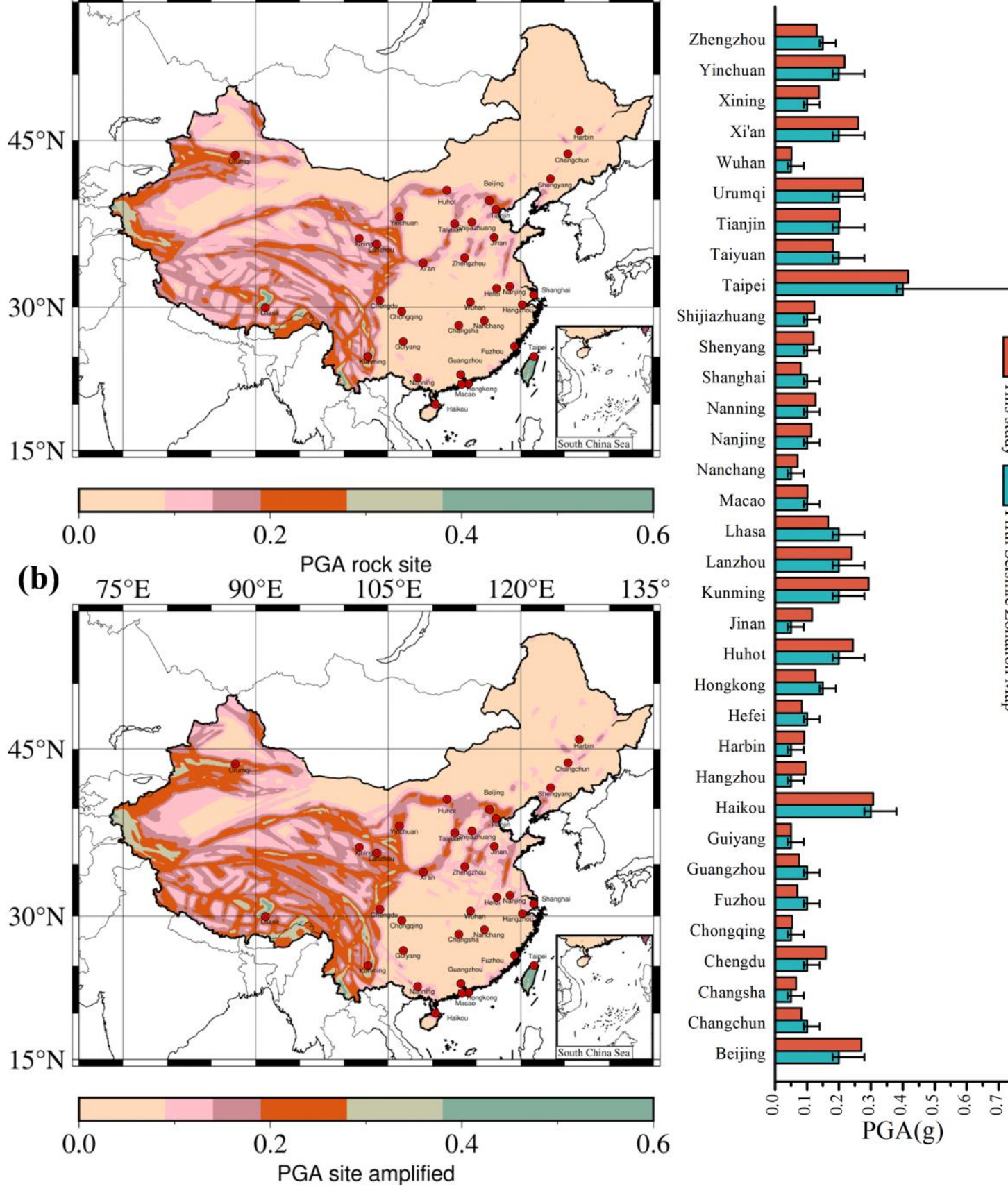

Shijiazhuang

Shenyang

Shanghai

Nanning

Nanjing

Nanchang

Macao $\longrightarrow$

Lhasa

Lanzhou

Kunming

Jinan एन

Huhot

Hongkong

Hefei

Harbin

Hangzhou

Haikou

Guiyang

Guangzhou

Fuzhou

Chongqing

Chengdu

Changsha

Changchun

Beijing

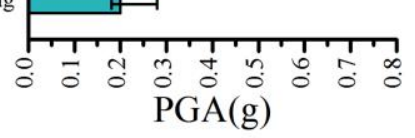

Fig. 2 Computed seismic hazard maps for mainland China: (a) 475-year MRP PGA for rock site condition $\left(V_{\mathrm{S} 30}=500 \mathrm{~m} / \mathrm{s}\right)$, and (b) site-amplified PGA for CL-II sites. (c) Comparison of PGA values from our calculated hazard maps (orange bars, referring to Chinese soil site Class II) and from the fifth-generation map for major cities (blue bars). Range of PGA bins for the fifth-generation map is illustrated using error bars. 
210 Using three-dimensional deaggregation techniques proposed by McGuire (1995), we 211 calculated the joint $\mathrm{M}-\mathrm{R}-\varepsilon$ distributions of contributions to the 475- and 2475-year MRP 212 hazard levels for the cities of Xichang, Xi'an, and Kunming (China). These three cities were 213 selected as examples because they are representative of different hazard levels in different 214 regions of China. The 475-year MRP hazard level for Xichang city $(0.32 \mathrm{~g})$ is larger than that 215 for the other two cities (Kuming: $0.27 \mathrm{~g}$; Xi' an: $0.23 \mathrm{~g}$ ). The bin widths for M, R, and $\varepsilon$ were 216 set as $0.5,5.0 \mathrm{~km}$, and 1.0 , respectively.

217 The joint M-R-E distributions for four target IMs: PGA, Sa (0.2 s), Sa (1.0 s), and Sa (2.0 218 s), regarding the 475- and 2475-year MRP hazard levels are illustrated in Figs. 3 and 4, 219 respectively. The 475-year MRP of the hazard level for Xichang is controlled by nearby 220 earthquakes (distance: 15-18 km) with large magnitude (7.25-7.5). For Kunming, as the period 221 of Sa increases, larger and more distant earthquake events control the hazard. The mean 222 magnitude $(\bar{M})$ is $6.6,6.9,7.3$, and 7.4 for PGA, Sa (0.2 s), Sa (1.0 s), and Sa (2.0 s), 223 respectively. The mean distance also increases from 19 to $36 \mathrm{~km}$ as the period increases. A 224 similar tendency is observed for Xi'an, with larger mean magnitude and greater distance for $225 \mathrm{Sa}(1.0 \mathrm{~s})$ and $\mathrm{Sa}(2.0 \mathrm{~s})$ than for PGA and $\mathrm{Sa}(0.2 \mathrm{~s})$. For Xichang and Kunming, the M and $\mathrm{R}$ 226 distribution results for the 2475-year MRP are similar to those of the 475-year MRP hazard 227 level. The differences are concentrated mainly in the value of $\varepsilon$, which increases from 1.1-1.2 228 to 1.6-1.7 for Xichang. For Kunming, the $\varepsilon$ value increases from 1.3-1.4 to 1.7-1.8. For Xi'an, 229 the magnitude regarding the 2475-year MRP is approximately 0.3 higher than the results for 230 the 475-year MRP, and the value of $\varepsilon$ increases from 0.9-1.0 to 1.3-1.4. 
(a)
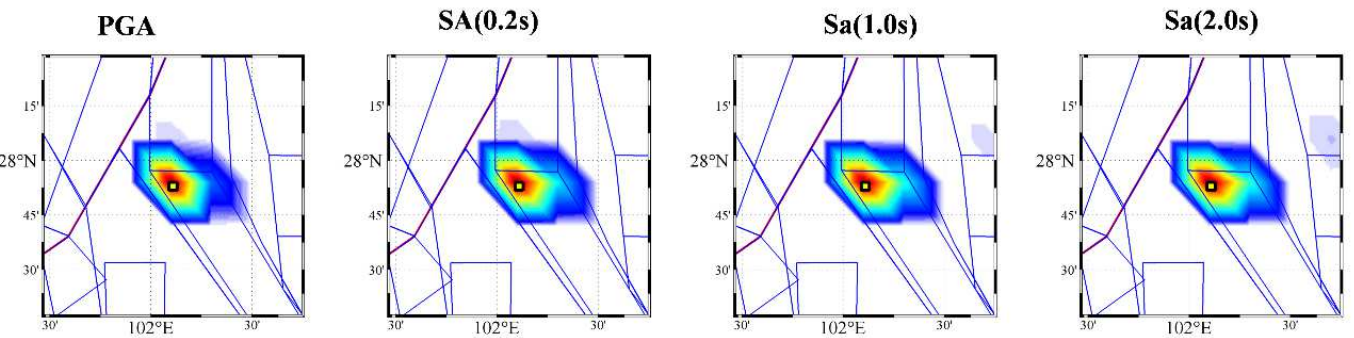

(b)
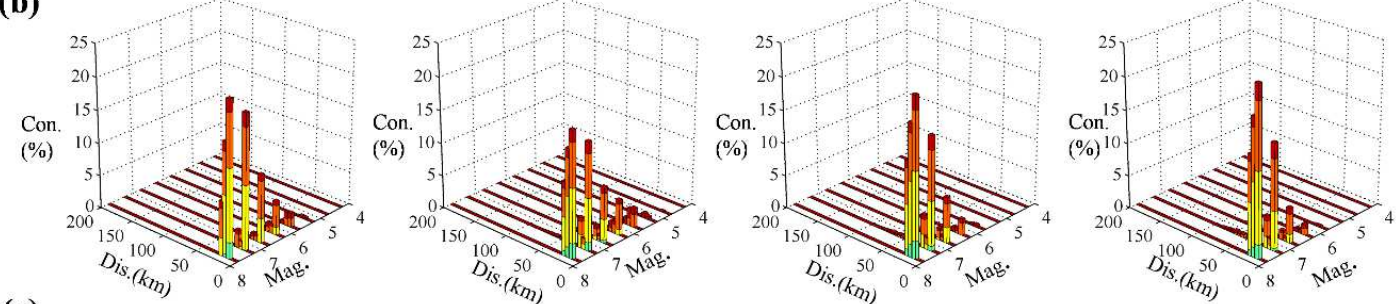

(c)
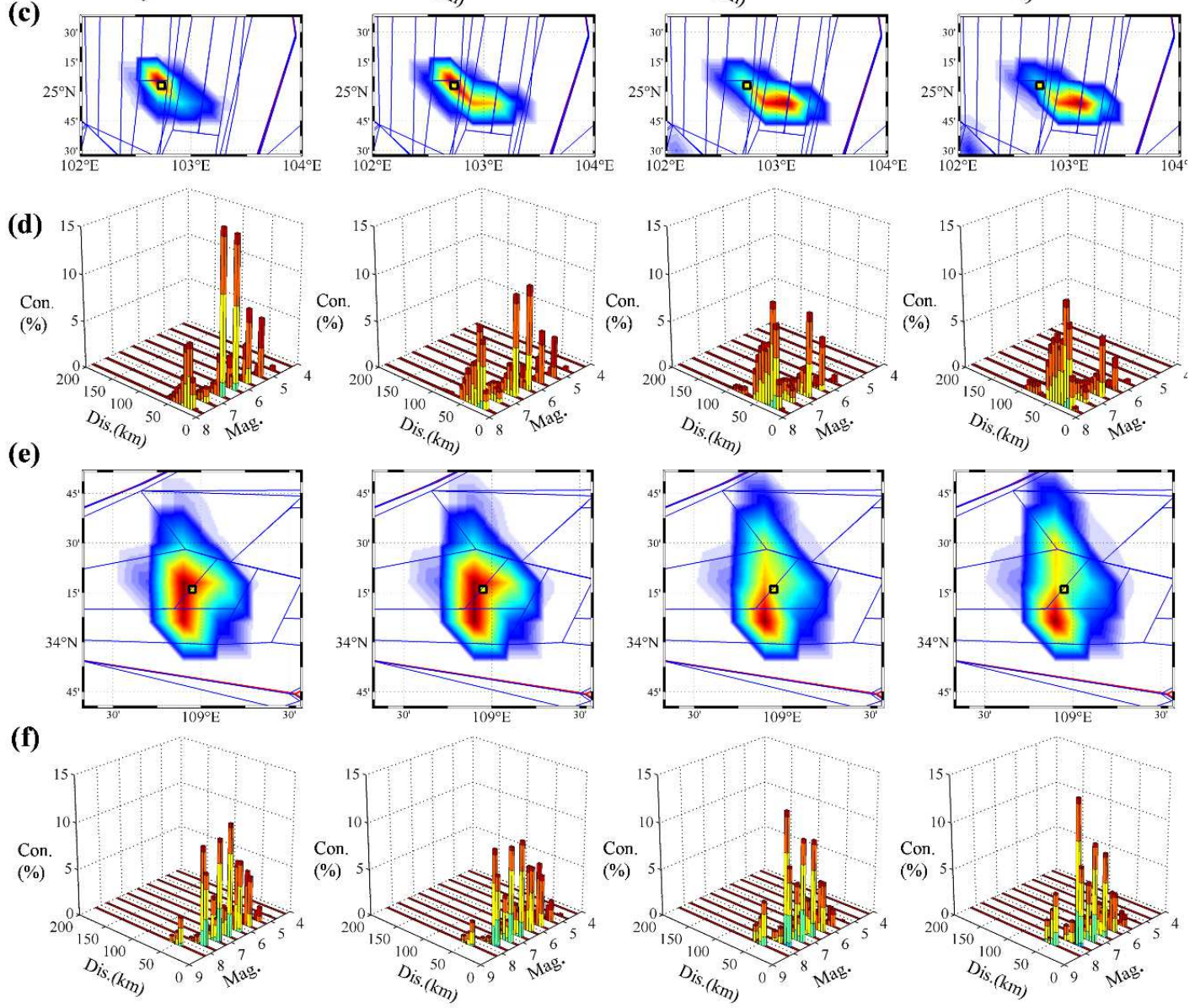

$\varepsilon$ bins:

$$
[-3,-2] \square[-2,-1] \square[-1,0] \square[0,1] \square[1,2] \square[2,3]
$$

Fig. 3 Contributions to hazard with MRP of 475 years for example cities, disaggregated in terms of latitude-longitude and joint $\mathrm{M}-\mathrm{R}-\varepsilon$ distribution regarding PGA, Sa (0.2 s), Sa (1.0 s), and Sa (2.0 s). The studied cities are (a) and (b) Xichang, (c) and (d) Kunming, and (e) and (f) Xi'an. 

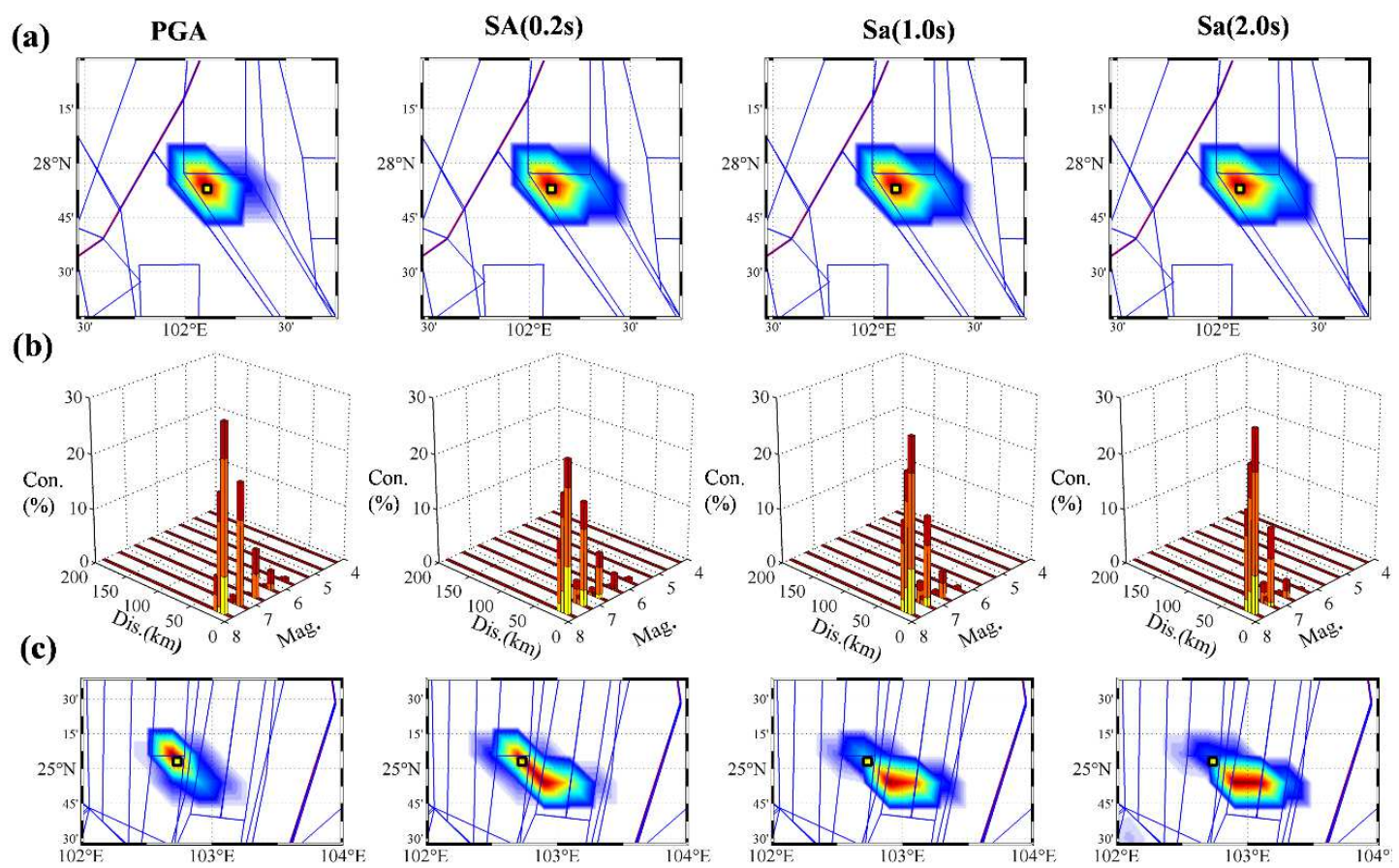

(d)
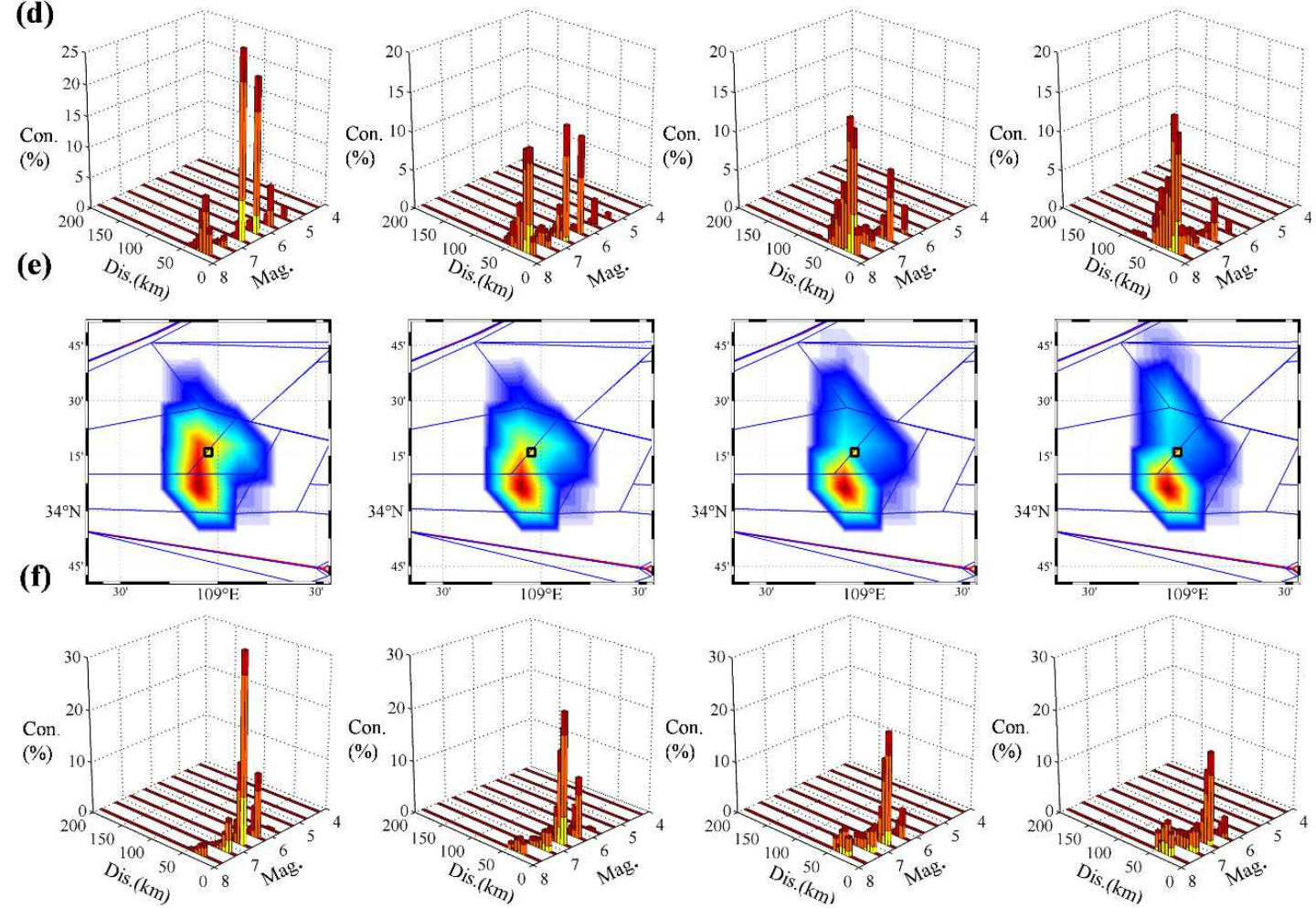

$\varepsilon$ bins:

$[-3,-2] \square[-2,-1]$

$\neg[-1,0] \square[0,1] \square[1,2] \square[2,3]$

Fig. 4 Contributions to hazard with MRP of 2475 years for example cities, disaggregated in terms of latitude-longitude and joint $\mathrm{M}-\mathrm{R}-\varepsilon$ distribution regarding PGA, Sa (0.2 s), Sa (1.0 s), and Sa (2.0 s). The studied cities are (a) and (b) Xichang, (c) and (d) Kunming, and (e) and (f) Xi'an. 
(a)
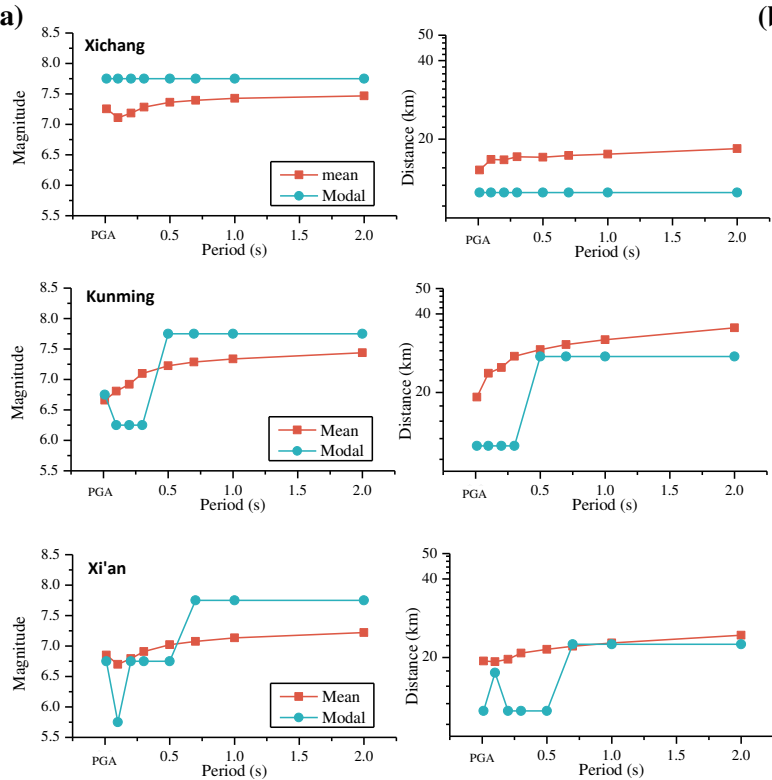

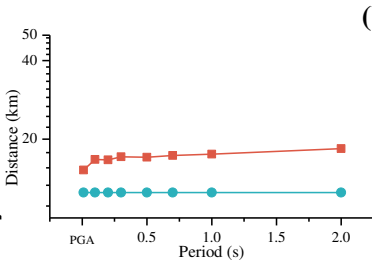

(b)

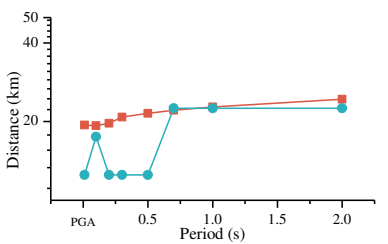

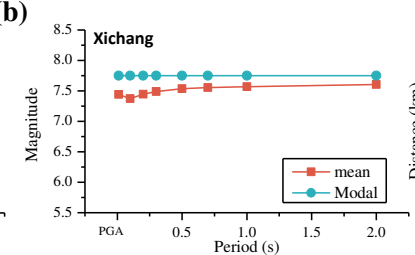
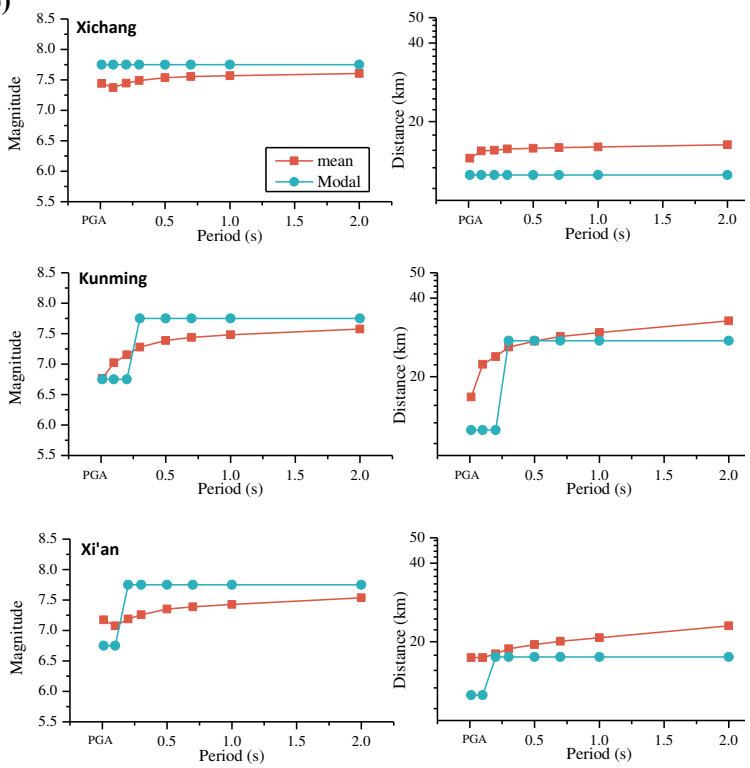

Fig. 5 Variation of the mean and modal values of $M$ and $R$ with spectral period for Xichang, Kunming, and Xi'an: (a) 475-year MRP and (b) 2475-year MRP.

The variations of the mean and modal values of $M$ and $R$ with different spectral periods for Xichang, Kunming, and Xi'an are shown in Fig. 5. For the 475- and 2475-year MRPs, the mean values $\bar{M}$ and $\bar{R}$ increase progressively with period, while the modal values $\mathrm{M}^{*}$ and $\mathrm{R}^{*}$ show a stepwise trend. This indicates that distant sources tend to control long-period Sa, while smaller earthquakes at shorter distances dominate at shorter periods. For a given spectral period, the mean and modal values of distance do not decrease with increasing MRP, which is perhaps more likely controlled by the $\varepsilon$ value for the three studied cities. However, the differences between the mean and modal values of $\mathrm{M}$ and $\mathrm{R}$ indicate that more than one event contributes significantly to the hazard; for example, the PGA at Kunming and Xi'an. In particular, as the discrepancy between $\bar{R}$ and $\mathrm{R}^{*}$ increases, the hazard tends to become controlled by both local and regional seismicity, suggesting a bimodal distribution (Harmsen, 2001).

In the joint $\mathrm{M}-\mathrm{R}-\varepsilon$ distributions cases, the strike direction of different source areas could generate results that are difficult to interpret because the applied YXL13 GMMs include two equations: one for along the direction of fault strike (long axis) and the other for perpendicular to fault strike (short axis). Therefore, we plotted the hazard deaggregation results in terms of latitude and longitude (Bazzurro \& Cornell, 1999) to illustrate the distribution of the spatial contributions in a typical map of potential source areas around the target cities, as illustrated in Figs. 3 and 4. As can be seen in Fig. 3(a), the spikes in the contour map have the same 
location, indicating that the dominant earthquake event for Xichang is controlled by the same

251 potential source area conditioned at four target IMs. In contrast, as illustrated in Fig. 3(c), the

252 spikes in the contour map for Kunming move from the nearest potential source area to a more 253 distant one, as the target IM changes from PGA to Sa (2.0 s). This indicates that a far-field 254 earthquake event dominates the IMs with longer period. For Xi' an, as illustrated in Fig. 3(d), 255 the spikes are spatially distributed in three potential source areas regarding PGA, while the 256 distribution gradually becomes concentrated in one of the potential sources as the period of $\mathrm{Sa}$ 257 increases from 0.2 to $2.0 \mathrm{~s}$. The overall tendency of the results regarding the 2475-year MRP, 258 as illustrated in Fig. 5, is largely the same as that for the 475-year MRP. These results of the 259 latitude-longitude deaggregation allow us to immediately identify the locations in the potential 260 source areas that dominate the hazard and better interpret the results of the joint $\mathrm{M}-\mathrm{R}-\varepsilon$ 261 distributions.

\section{Construction of pseudo-exact conditional spectrum}

263 We would further construct the conditional spectrum (CS) based on the joint $\mathrm{M}-\mathrm{R}-\varepsilon$ 264 deaggregation and magnitude-longitude-latitude deaggregation results respectively. The concept of conditional mean spectrum (CMS) was firstly introduced by Baker and Cornell 266 (2006). The target spectral acceleration $S a\left(T^{*}\right)$ at a given period $T^{*}$ (e.g. the fundamental 267 vibration period of a structure) is obtained from PSHA results (Baker and Cornell 2005). The resulting spectrum, which includes the conditional standard deviation of $\ln S a(T)$, is referred to as the Conditional Spectrum and abbreviated hereafter as CS (Lin et al., 2013a). In current practice, the approximate CS was calculated using a single GMM and single earthquake scenario, which is often taken from the mean value of the causal magnitudes and distances deaggregation results. To consider the contributions of multiple causal earthquakes and different GMMs, the concept of the exact CS was originally proposed by Lin et al(2013a). To account for all the branch weights in PSHA logic threes, the exact CS were constructed using the deaggregation results with respect to all the input parameters in the GMMs, or be derived during the PSHA computation process by implementing each and every earthquake source and logic-tree branch.

In our case, the joint $\mathrm{M}-\mathrm{R}-\varepsilon$ deaggregation did not provide the strike direction information in YLX13 GMMs. Therefore, we propose to use the magnitude-longitude-latitude deaggregation results to build the pseudo-exact CS by implementing the probability of different 
282 did not calculate the accurate CPSHA logic-tree weight for each and every potential source as 283 in the exact CS.

284 Supposing that there are two possible strike directions for the potential source area: strike 285 direction $\alpha$ and strike direction $\beta$. For each point source and strike direction considered, we 286 could obtain the corresponding conditional mean spectrum $\mu_{\ln S a_{1}(T i) \mid \ln S a\left(T^{*}\right)}, \mu_{\ln S a_{2}(T i) \mid \ln S a\left(T^{*}\right)}$, and 287 conditional standard deviation values $\sigma_{\ln S a(T i) \ln S a\left(T^{*}\right)}$ as follows.

$$
\begin{aligned}
& \mu_{\ln S a_{1}(T i) \mid \ln S a\left(T^{*}\right)}=\mu_{\ln S a(T i)}\left(M, R, \text { azimuth, region, strike }{ }_{\alpha}\right)+\rho\left(T^{*}, T_{i}\right) \varepsilon_{1}\left(T^{*}\right) \sigma_{\ln S a_{1}\left(T_{i}\right)} \\
& \mu_{\ln S a_{2}(T i) \mid \ln S a\left(T^{*}\right)}=\mu_{\ln S a(T i)}\left(M, R, \text { azimuth, region, strike }{ }_{\beta}\right)+\rho\left(T^{*}, T_{i}\right) \varepsilon_{2}\left(T^{*}\right) \sigma_{\ln S a_{2}\left(T_{i}\right)} \\
& \sigma_{\ln S a_{1}\left(T_{i}\right)}=\sigma_{\ln S a_{2}\left(T_{i}\right)}=\sigma_{\ln S a\left(T_{i}\right)}, \text { and } \sigma_{\ln S a(T i) \mid \ln S a\left(T^{*}\right)}=\sigma_{\ln S a\left(T_{i}\right)} \sqrt{1-\rho^{2}\left(T^{*}, T_{i}\right)}
\end{aligned}
$$

Where mean and standard deviation predicted by the YLX13 GMM were denoted $\mu_{\mathrm{ln} S a(T i)}$ and $\sigma_{\ln S a(T i)}$. The magnitude $(M)$, source-to-site distance $(R)$, azimuth angle of the site-tosource line, and strike direction of potential source area are input parameters of the YLX13 GMM. The $\varepsilon_{1}\left(T^{*}\right)$ and $\varepsilon_{2}\left(T^{*}\right)$ indicated the number of standard deviations which the $S a(T i)$ 292 differs from the mean spectral value predicted by the YLX13 GMM. Correlation coefficient 293 between pairs of $\varepsilon$ values at two periods, $\rho\left(T^{*}, T_{i}\right)$, were computed using the empirical 294 equation proposed by Baker and Jayaram (2008).

295 The magnitude-longitude-latitude deaggregation results provide the weights, $w_{k}$, which 296 indicate the contribution of $k$ th grid point in the potential sources to the target occurrence of 297 the $S a(T)$. For the specific potential source area, the probability value for the strike direction $\alpha$, $298 \beta$ were $P_{\mathrm{k} 1}$ and $P_{\mathrm{k} 2}$ respectively, which were implemented in the CPSHA procedure. For each 299 specific potential source area in our CPSHA procedure, one of the four region-specify YLX13 300 GMMs were utilized. Therefore the logic tree weight of different region-specify GMMs need 301 not to be considered in construction of the pseudo-exact CS. According to the total probability 302 theory, the $\mu_{\ln S a(T i) \mid \ln S a\left(T^{*}\right)}$ and $\sigma_{\ln S a(T i) \mid \ln S a\left(T^{*}\right)}$ of the pseudo-exact CS can be derived as follows:

$$
\mu_{\ln S a(T i) \mid \ln S a\left(T^{*}\right)}=\sum_{k} w_{k}\left(P_{k 1} \times \mu_{\ln S a_{1}(T i) \mid \ln S a\left(T^{*}\right)}+P_{k 2} \times \mu_{\ln S a_{2}(T i) \mid \ln S a\left(T^{*}\right)}\right)
$$




$$
\begin{aligned}
& \sigma_{\ln S a(T i) \mid \ln S a\left(T^{*}\right)}=\sqrt{\begin{array}{l}
\sum_{k} w_{k}\left\{P_{k 1} \times\left[\sigma_{\ln S a(T i) \mid \ln S a\left(T^{*}\right)}^{2}+\mu_{\ln S a_{1}(T i) \mid \ln S a\left(T^{*}\right)}^{2}-\mu_{\ln S a(T i) \mid \ln S a\left(T^{*}\right)}^{2}\right]+\ldots\right. \\
\left.\ldots P_{k 2} \times\left[\sigma_{\ln S a(T i) \| \ln S a\left(T^{*}\right)}^{2}+\mu_{\ln S a_{2}(T i) \mid \ln S a\left(T^{*}\right)}^{2}-\mu_{\ln S a(T i) \mid \ln S a\left(T^{*}\right)}^{2}\right]\right\}
\end{array}} \\
& =\sqrt{\begin{array}{c}
\sigma_{\ln S a(T i) \mid \ln S a\left(T^{*}\right)}^{2}+\sum_{k} w_{k}\left[P_{k 1} \times\left(\mu_{\ln S a_{1}(T i) \mid \ln S a\left(T^{*}\right)}^{2}-\mu_{\ln S a(T i) \mid \ln S a\left(T^{*}\right)}^{2}\right)+\ldots\right. \\
\left.\ldots P_{k 2} \times\left(\mu_{\ln S a_{2}(T i) \mid \ln S a\left(T^{*}\right)}^{2}-\mu_{\ln S a(T i) \mid \ln S a\left(T^{*}\right)}^{2}\right)\right]
\end{array}}
\end{aligned}
$$

The hazard deaggregation results of three example cities illustrated in the previous section are used herein to construct the pseudo-exact CS according to Eq. (9) and (10). The Sa ( $T^{*}=0.2$ s) and $\mathrm{Sa}\left(T^{*}=1.0 \mathrm{~s}\right)$ values corresponding to 2475 -yr MRP are selected as conditional target spectral acceleration. For comparison reason, we also computed the approximate CS using the mean earthquake scenario $(\bar{M}, \bar{R})$ obtained from the joint $\mathrm{M}-\mathrm{R}-\varepsilon$ deaggregation results as shown in Fig.3 and Fig,4. Long-axis and short-axis YLX13 GMM were utilized respectively for computation of the approximate CS.
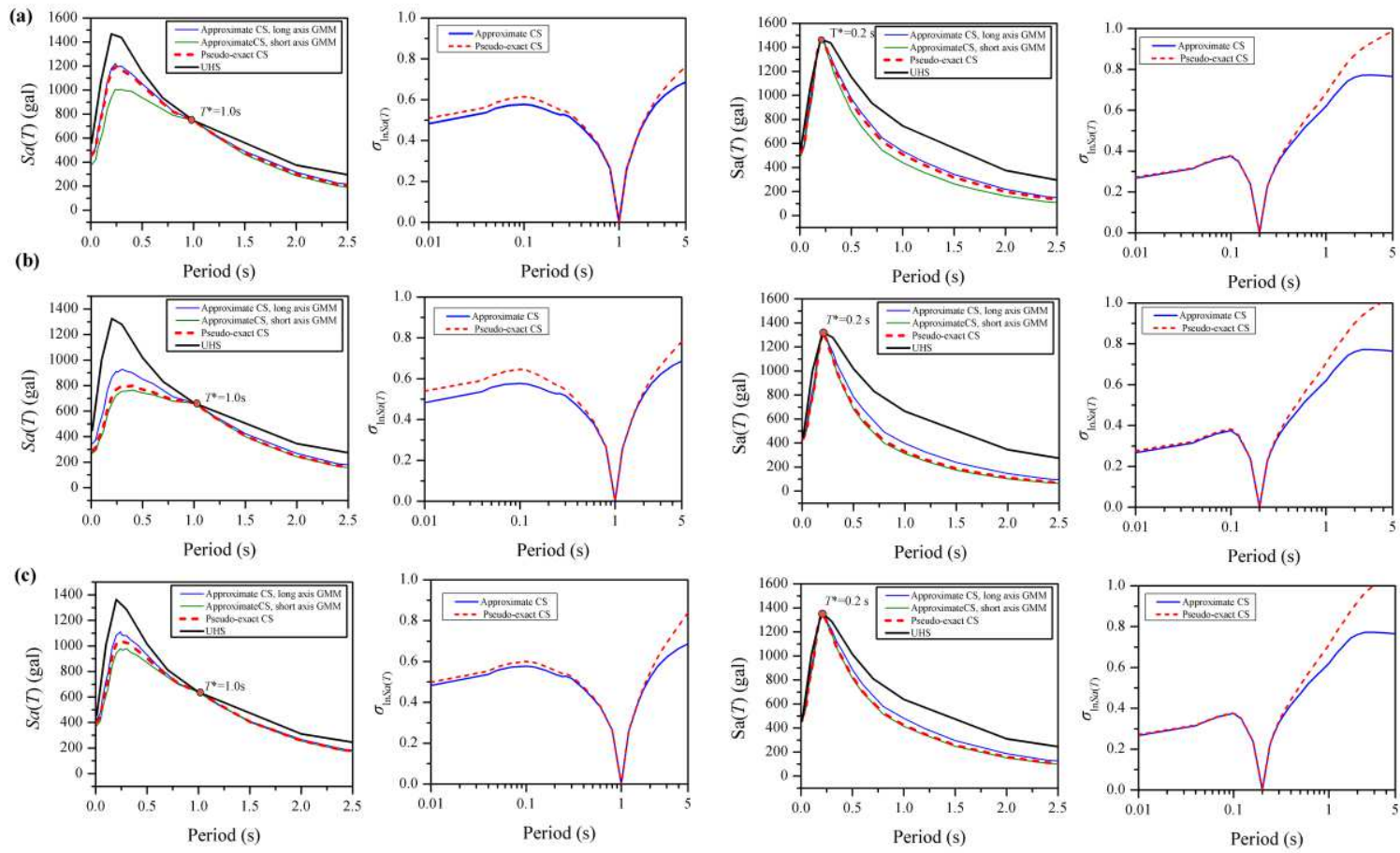

Fig. 6 Mean conditional mean spectrum and conditional standard deviation for (a) Xichang, (b) Kunming, and (c) Xi' an city respectively regarding $\mathrm{Sa}\left(T^{*}=0.2 \mathrm{~s}\right)$ and $\mathrm{Sa}\left(T^{*}=1.0 \mathrm{~s}\right)$ with 2475-yr MRP (2\% probability of exceedance in 50 years). The results were compared between: approximate CS using mean earthquake scenario and pseudo-exact CS derived from using the magnitude-longitude-latitude deaggregation results 
The conditional mean and variance results for approximate CS and pseudo-exact CS were 311 illustrated in Fig.6. For three target example cities, the pseudo-exact conditional mean 312 spectrum results lies between the approximate CS results using the long axis and short axis 313 YLX13 GMM. The results indicated that using the geometric mean value of the approximate 314 CS results of the long axis and short axis YLX13 GMM might also be a promising practical 315 way to estimate the mean value of the exact CS without further computation effort relied on 316 the mag-longitude-latitude deaggregation results. We would further evaluate its hazard 317 consistency in the next section. On the other hand, the conditional standard deviation of the 318 pseudo-exact CS is as expected greater than the approximate CS. There are two parts of 319 contribution to the conditional standard deviation regarding pseudo-exact CS as illustrated in 320 Eq.(10): (1) contribution from $\sigma_{\ln S a(T)}$, variance in estimated $S a$ for a given potential source 321 point and magnitude; which is fixed in our case; (2) contribution from $\mu_{\ln S a(T)}$, variance in the 322 variation between the location of the potential source point and the corresponding strike 323 direction. The approximate CS consider only mean $(\bar{M}, \bar{R})$ values and thus cannot identify the 324 uncertainty from $\mu_{\ln S a(T)}$ of multiple source points and possible strike directions. As illustrated 325 in Fig. 6, the difference indicates that the variance of expectations contribution were not 326 negligible in estimation of the conditional standard deviation. To measure the difference, the 327 ratio between the conditional standard deviation of exact-CS and the result of the approximate 328 CS were plotted with period ranging from $0.01 \mathrm{~s}$ to $10.0 \mathrm{~s}$ in Fig.7. The difference is more 329 significant for the period far away from the conditional target period $T^{*}$, of which the maximum 330 ratio value could reach approximately 1.25 to 1.5 .
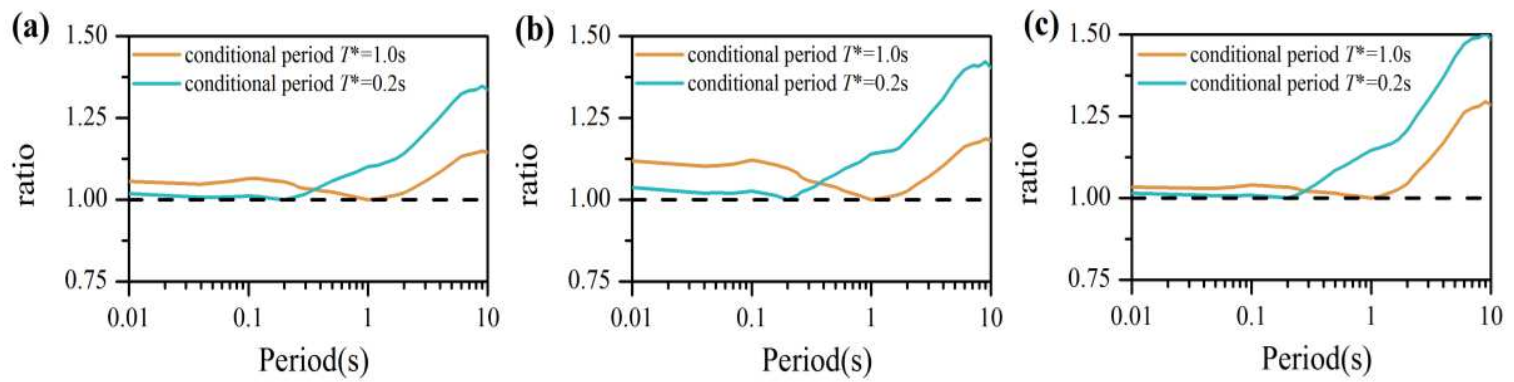

Fig. 7 The ratio between the conditional standard deviation of pseudo-exact CS and approximate CS regarding (a) Xichang (b) Kunming, and (c) Xi'an city respectively. 


\section{Hazard Consistency Validation}

332 Hazard consistency is one of the key features of the CS, which ensures ground motion 333 records selected based on the CS distribution independently of the choice of the conditioning 334 period (Lin et al. 2013b). For this purpose, we would next verify the hazard consistency of the 335 ground motions matching pseudo-exact CS and approximate CS. It is accomplished by comparing between the annual exceedance probability and the hazard curve at different conditional periods. The annual exceedance probability rate of the selected ground motions at a given period $T$ can be evaluated using the following equation proposed by Lin et al. (2013b).

$$
\lambda(S a(T)>y)=\int_{x} P\left(S a(T)>y \mid S a\left(T^{*}\right)=x\right) \mid \mathrm{d} \lambda\left(S a\left(T^{*}\right)>x \mid\right.
$$

where $\lambda(S a(T)>y)$ denotes the rate of exceedance of $S a(T)$ induced by the ground motions selected conditional on $S a\left(T^{*}\right)$, and $P\left(S a(T)>y \mid S a\left(T^{*}\right)=x\right)$ is the probability that a selected ground motion scaled to have $S a\left(T^{*}\right)=x$ has also an amplitude $S a(T)$ higher than a given value $y$.

The consistency between selected ground motions and the target CS would directly influence the consistency with the target seismic hazard curve. Although the greedy optimization technique proposed by Jayaram et al (2011) significantly improves the match performance between the target distribution, it is still very hard to select satisfactory ground motion sets at extremely high $\mathrm{Sa}\left(T^{*}\right)$ amplitude which is necessary in hazard consistency validation work. The approximate CS follows the multivariate lognormal distribution. Therefore we utilized the Latin hypercube sampling techniques to get the random realizations that having the same mean, variance, and correlation structure with the target CS distribution.

351 The probability $P\left(S a(T)>y \mid S a\left(T^{*}\right)=x\right)$ in Eq.(11) were estimated as the fraction of the realizations with $S a\left(T^{*}\right)=x$ that also satisfy $S a(T)>y$.

For multivariate lognormal distribution, the $i$ th row, $k$ th column element of the correlation 354 matrix is:

$$
\rho_{\left(\ln S a_{i}\left|S a_{j}, \ln S a_{k}\right| S a_{j}\right)}=\left\{\begin{array}{cc}
\frac{\rho_{i k}-\rho_{i j} \rho_{k j}}{\sqrt{1-\rho_{i j}^{2}} \sqrt{1-\rho_{k j}^{2}}} & i \neq k \\
1 & i=k
\end{array}\right.
$$

355 Where $\rho_{i k}=\rho_{\ln S a_{i}, \ln S a_{k}}$, stands for the correlation between $\ln S a_{i}$ and $\ln S a_{k}$, which was obtained 356 from empirical correlation equations developed by Baker and Jayaram (2008). The covariance 357 matrix of the target approximate CS distribution could be derived as follows: 


$$
\operatorname{Cov}_{\left(\ln S a_{i}\left|S a_{j}, \ln S a_{k}\right| S a_{j}\right)}=\rho_{\left(\ln S a_{i}\left|S a_{j}, \ln S a_{k}\right| S a_{j}\right)} \sigma_{\ln S a_{i} \mid \ln S a_{j}} \sigma_{\ln S a_{k} \mid \ln S a_{j}}
$$

358 For pseudo-exact CS, the conditional logarithmic Sa distribution is not Gaussian when 359 multiple causal earthquakes and strike directions are considered. A two step simulation 360 approach was proposed by Bradley et al(2010) to generate realizations that have consistent 361 mean, standard deviation and correlation structure with the target multivariate distribution. We 362 use the same procedure to generate realizations for pseudo-exact CS distribution at different 363 hazard level.

364 The hazard consistency of spectral accelerations of the realizations matching CS for Xichang, 365 Kunming, and Xi' an city were evaluated as example cases. The seismic hazard deaggregation 366 for these three cities were repeated and applied for 10 discrete $S a\left(T^{*}\right)$ amplitudes at conditional 367 period $0.2 \mathrm{~s}$ and $1.0 \mathrm{~s}$. For each target $\mathrm{Sa}\left(T^{*}\right)$ amplitude, 100 realizations were generated to 368 match target distribution of the approximate CS and pseudo-exact CS respectively. The 369 geometric mean values of the approximate CS using long and short axis of YLX13 GMMs 370 were utilized here. 

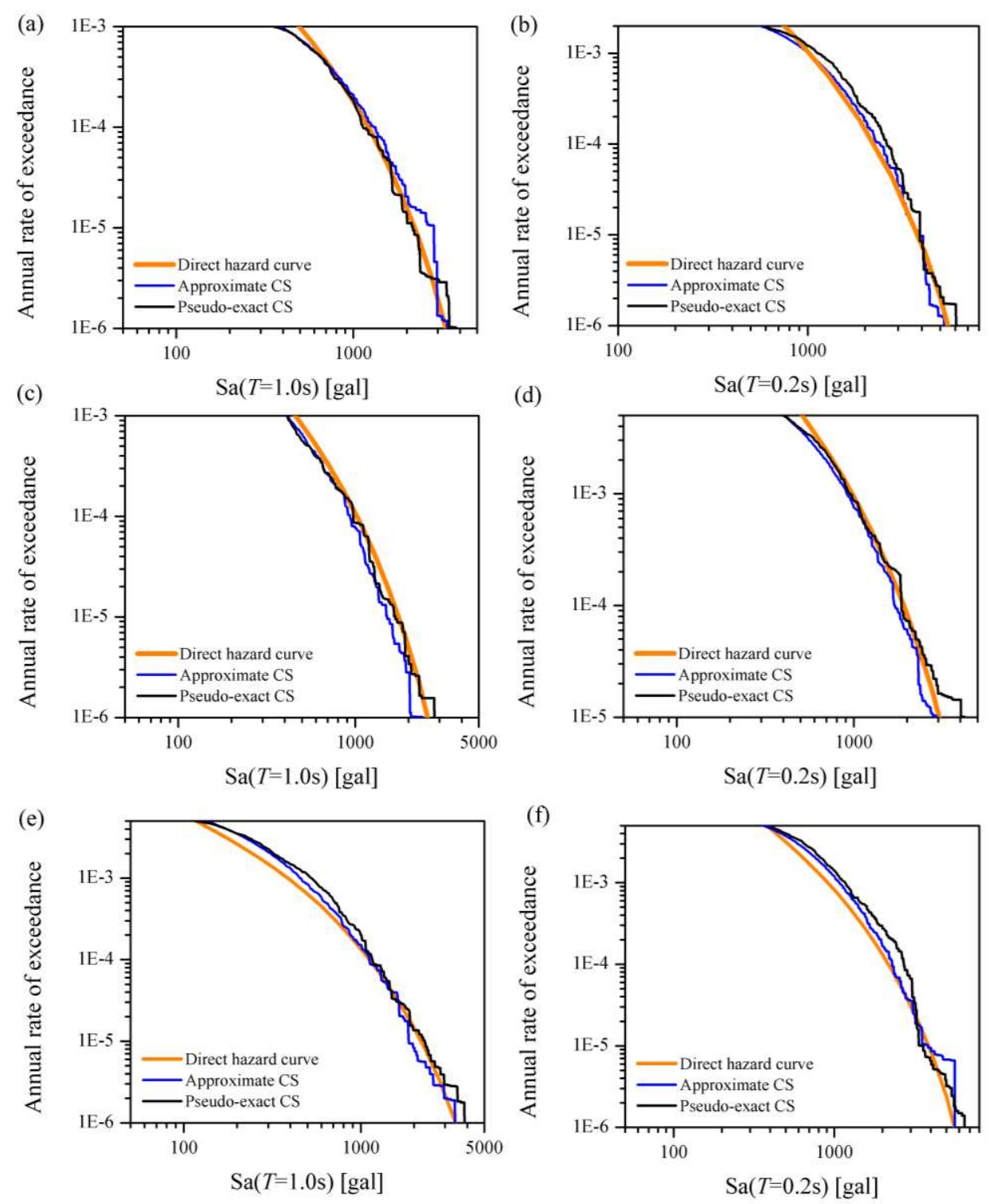

Fig. 8 Comparsion between obtained annual exceedance rate versus corresponding hazard curves at conditional periods 1.0s and 0.2s. The results are compared for (a)(b) Xichang, (c)(d) Kunming City, and (e)(f) Xi'an City respectively.

372 The obtained annual exceedance rate of the $100 \times 10$ realizations with $\mathrm{Sa}(T)>\mathrm{y}$ 373 corresponding to conditional period $T^{*}=0.2 \mathrm{~s}$ and $2.0 \mathrm{~s}$ were illustrated in Fig. 8. For 374 comparison purpose, the corresponding ground motion hazard curves for $0.2 \mathrm{~s}$ and $2.0 \mathrm{~s}$ were 375 also plotted in the same figure. The stepped shape of the obtained annual exceedance rate 376 curves are caused by the discrete $S a\left(T^{*}\right)$ amplitudes. Generally, the obtained annual 377 exceedance rate shows good agreement with corresponding ground motion hazard curves at 
378 both $0.2 \mathrm{~s}$ and $2.0 \mathrm{~s}$. Similar observations are found for all three example cities. At low 379 exceedance rate, the obtained annual exceedance rate are more close to the true hazard curve 380 when using the pseudo-exact CS as target distribution. For Xichang and Xi' an city, slight bias 381 were found at the high exceedance rate, which are mainly because the deaggregation bins could 382 not be set too small due to the computation capacity limit. In the work of Lin et al (2013b), the 383 conditional standard deviations of approximate CS were inflated by a constant $10 \%$ to make 384 the selected ground motion could match the hazard level. In our examples, the inflation of 385 standard deviation for approximate CS may improve the hazard consistency results at low exceedance rate, while the bias between target hazard curve at high exceedance rate would be more significant. Therefore it is suggested that the geometric mean approximate CS being directly used for ground motion selection without inflation of the standard deviation when the target exceedance rate are not too low.

\section{Conclusions}

To perform deaggregation of the seismic hazard for China, we constructed a hazard map using the YLX13 GMMs, tri-level seismicity models, and the CPSHA scheme, as used to produce the fifth-generation national Seismic Ground Motion Parameter Zonation Map. Comparison revealed that our calculated PGA values for 34 principal cities in China were consistent with those of the fifth-generation zonation map, indicating that our hazard map and corresponding deaggregation results could be further applied in current engineering practice in China. Joint $\mathrm{M}-\mathrm{R}-\varepsilon$ distributions and longitude-latitude distributions of the contributions to different hazard levels for three example cities (Xichang, Kunming, and Xi'an) were illustrated and interpreted. The results clearly identified the locations in the potential source areas that dominate the hazard of the target cities. As expected, distant and larger earthquakes tend to control long-period Sa, while smaller events at shorter distances dominate the shorter periods. For a given spectral period, the mean and modal values of magnitude or distance did not change substantially as the MRP increased, indicating that the hazard level of the three example cities is more likely controlled by the $\varepsilon$ value.

The magnitude-longitude-latitude deaggregation results and the probability of strike direction of potential source was implemented to build the pseudo-exact CS. The mean

407 pseudo-exact CS is close to the geometric mean approximate CS using long and short axis 408 GMMs, and the conditional standard deviation is approximately 1.1 to 1.5 times larger than 
409 the approximate CS. Hazard consistency of the spectral accelerations of the ground motion

410 realizations matching target pseudo-exact CS and approximate CS distribution were validated.

411 For studied three city. generally good agreement is observed between the obtained annual

412 exceedance rate and corresponding direct hazard curves at both $0.2 \mathrm{~s}$ and $2.0 \mathrm{~s}$. The geometric

413 mean values of the approximate CS using long and short axis YLX13 GMMs is a practical

414 choice when the target conditional spectral acceleration amplitude was not set too high.

415 For convenient use of our results in potential engineering applications, we calculated mean

416 earthquake scenario $(\bar{M}, \bar{R}, \bar{\varepsilon})$, and modal earthquake scenario $\left(M^{*}, R^{*}, \varepsilon^{*}\right)$ values 417 corresponding to the 475- and 2475-year MRP hazard for 34 principal cities in mainland China.

418 The computed results were tabulated and uploaded at the open-source GitHub platform. 419 https://github.com/JIKUN1990/China-Seismic-Hazard-Deaggregation-34cities

\section{$421 \quad$ Data and Resources}

422 The results calculated in this study for 34 principal cities in mainland China are freely 423 accessed on the open-source GitHub platform: https://github.com/JIKUN1990/China424 Seismic-Hazard-Deaggregation-34cities

\section{Acknowledgements}

426 The authors are grateful to the associated researcher Dr. Li Changlong from the Institute of 427 Geophysics of the China Earthquake Administration for providing useful guidance regarding 428 the construction of the China hazard map and technique details explanation. The open-source 429 Generic Mapping Tools software was used to produce some of the figures in this paper. The 430 OpenQuake Platform (https://platform.openquake.org/) developed by the GEM Foundation is 431 acknowledged for the hazard assessment work in this study (Pagani et al., 2014).

\section{Fundings}

433 This work was partly supported by the Chinese National Natural Science Fund (grant number: 434 51908518). Heilongjiang Provincial Natural Science Foundation of China (grant number. 435 LH2020E022); Preferential funding for returned overseas Chinese Scholars in Heilongjiang; 436 Science Foundation of the Institute of Engineering Mechanics, CEA (grant number. 2019B09); 


\section{Declaration of conflicting interests}

438 All authors certify that they have no affiliations with or involvement in any organization or 439 entity with any financial interest or non-financial interest in the subject matter or materials 440 discussed in this manuscript.

\section{$441 \quad$ References}

442 Baker, J. W. (2011). Conditional mean spectrum: tool for ground-motion selection. Journal of 443 Structural Engineering-ASCE, 137(3), 322-331. https://doi.org/10.1061/(asce)st.1943$444 \quad \underline{541 x .0000215}$

445 Baker, J. W., and Cornell, C. A. (2005). A vector-valued ground motion intensity measure 446 consisting of spectral acceleration and epsilon. Earthquake Engineering \& Structural Dynamics, 34(10), 1193-1217. https://doi.org/10.1002/eqe.474

448 Baker, J. W., and Cornell, C. A. (2006). Spectral shape, epsilon and record selection. 449 Earthquake Engineering \& Structural Dynamics, 35(9), 1077-1095. $450 \quad$ https://doi.org/10.1002/eqe.571

451 Baker, J. W., and Jayaram, N. (2008). Correlation of spectral acceleration values from NGA 452 ground motion models. Earthquake Spectra, 24(1), 299-317.

454 Baker, J. W., and Lee, C. (2018). An improved algorithm for selecting ground motions to match 455 a conditional spectrum. Journal of Earthquake Engineering, 22(4), 708-723. $\underline{\text { https://doi.org/10.1080/13632469.2016.1264334 }}$

Bazzurro, P., and Cornell, C. A. (1999). Disaggregation of seismic hazard. Bulletin of the 458 Seismological Society of America, 89(2), 501-520.

459 Bender, B. (1986). Modeling source zone boundary uncertainty in seismic hazard analysis. 460 Bulletin of the Seismological Society of America, 76(2), 329-341. 
461 Bradley, B. A. (2010). A generalized conditional intensity measure approach and holistic 462 ground-motion selection. Earthquake Engineering \& Structural Dynamics, 39(12), 13211342. https://doi.org/10.1002/eqe.995

464 Bradley, B. A. (2012). A ground motion selection algorithm based on the generalized 465 conditional intensity measure approach. Soil Dynamics \& Earthquake Engineering, 40, 48-

466 61. https://doi.org/10.1016/j.soildyn.2012.04.007

467 China Earthquake Administration, CEA. (2015). Seismic ground motion parameters zonation map of China (GB 18306-2015). Beijing: Seismological Press. (in Chinese)

469 Cornell, C. A. (1968). Engineering seismic risk analysis. Bulletin of the Seismological Society $470 \quad$ of America, 58(5), 1583-1606.

471 Gao, M (ed.). (2015). Publicizing materials of GB 18306-2015 Chinese ground motion 472 parameter zoning map. Beijing: China Standard Press. (in Chinese).

473 Harmsen, S. C. (2001). Mean and modal in the deaggregation of probabilistic ground motion. 474 Bulletin of the Seismological Society of America, 91(6), 1537-1552. $475 \quad$ https://doi.org/10.1785/0120000289

Jayaram, N., Lin, T., and Baker, J. W. (2011). A computationally efficient ground-motion selection algorithm for matching a target response spectrum mean and variance. Earthquake Spectra, 27(3), 797-815. https://doi.org/10.1193/1.3608002

Ji, K., Bouaanani, N., Wen, R. and Ren, Y. (2018). Introduction of conditional mean spectrum and conditional spectrum in the practice of seismic safety evaluation in China. Journal of Seismology, 22(4), 1005-1024. https://doi.org/10.1007/s10950-018-9747-8

Ji, K., Ren, Y., and Wen, R. (2017). Site classification for National Strong Motion Observation 483 Network System (NSMONS) stations in China using an empirical H/V spectral ratio 484 method. Journal of Asian Earth Sciences, 147, 79-94. $485 \quad$ https://doi.org/10.1016/j.jseaes.2017.07.032 
Lin, T., Harmsen, S. C., Baker, J. W., and Luco, N. (2013a). Conditional spectrum computation incorporating multiple causal earthquakes and ground-motion prediction models. Bulletin of the Seismological Society of America, 103(2A), 1103-1116. https://doi.org/10.1785/0120110293

490

Lin, T., Haselton, C. B., and Baker, J. W. (2013b). Conditional spectrum-based ground motion selection. Part I: hazard consistency for risk-based assessments. Earthquake engineering \& structural dynamics, 42(12), 1847-1865. https://doi.org/10.1002/eqe.2301

Lu, H. and Zhao, F. (2007). Site coefficients suitable to China site category. Acta Seismologica Sinica, 20(1), 71-79. https://doi.org/10.1007/s11589-007-0071-6

Lv, D. G., Liu, T., Li, S., Jia, X., Pang, J. and Yu, X. (2017) Probability seismic hazard analysis, deaggregation and scenario earthquake with application to Xi'an region. Earthquake Engineering and Engineering Dynamics. 38(5), 12-21.(in Chinese with English abstract)

McGuire, and R. K. (1995). Probabilistic seismic hazard analysis and design earthquakes: closing the loop. Bulletin of the Seismological Society of America, 85, 1275-1284.

Ministry of Housing and Urban-Rural Construction of the People's Republic of China (MHURC). (2016). Code for seismic design for buildings (GB 50011-2010) 2016 edition. Beijing: China Architecture \& Building Industry Press. (in Chinese)

National Research Council (NRC). (1988). Probabilistic seismic hazard analysis, in Report on the Panel on Seismic Hazard Analysis, National Academy Press, Washington D.C.

Pagani, M., Monelli, D., Weatherill, G., Danciu, L., Crowley, H., Silva, V., Henshaw, P., Butler, L., Nastasi. M., Panzeri. L., Simionato, M., and Vigano, D. (2014). OpenQuake engine: An open hazard (and risk) software for the global earthquake model. Seismological Research Letters , 85, 692-702. https://doi.org/10.1785/0220130087

Wen, R., Ji, K., and Ren, Y.. (2018). The real ground motion records selection for seismic design code in China. 16th European Conference. 
511 Yu, Y., S. Li, and L. Xiao. (2013). Development of ground motion attenuation relations for the

512 new seismic hazard map of China. Technology for Earthquake Disaster Prevention, 8, 24-

513 33. (in Chinese with English abstract)

514 Zhou, B. G. and Sun, J. B. (2000). Advances in delineation of potential seismic sources in 515 China. Journal of Earthquake Predication Research, 8(1), 92-103. (in Chinese with English 516 abstract)

517 
(a)
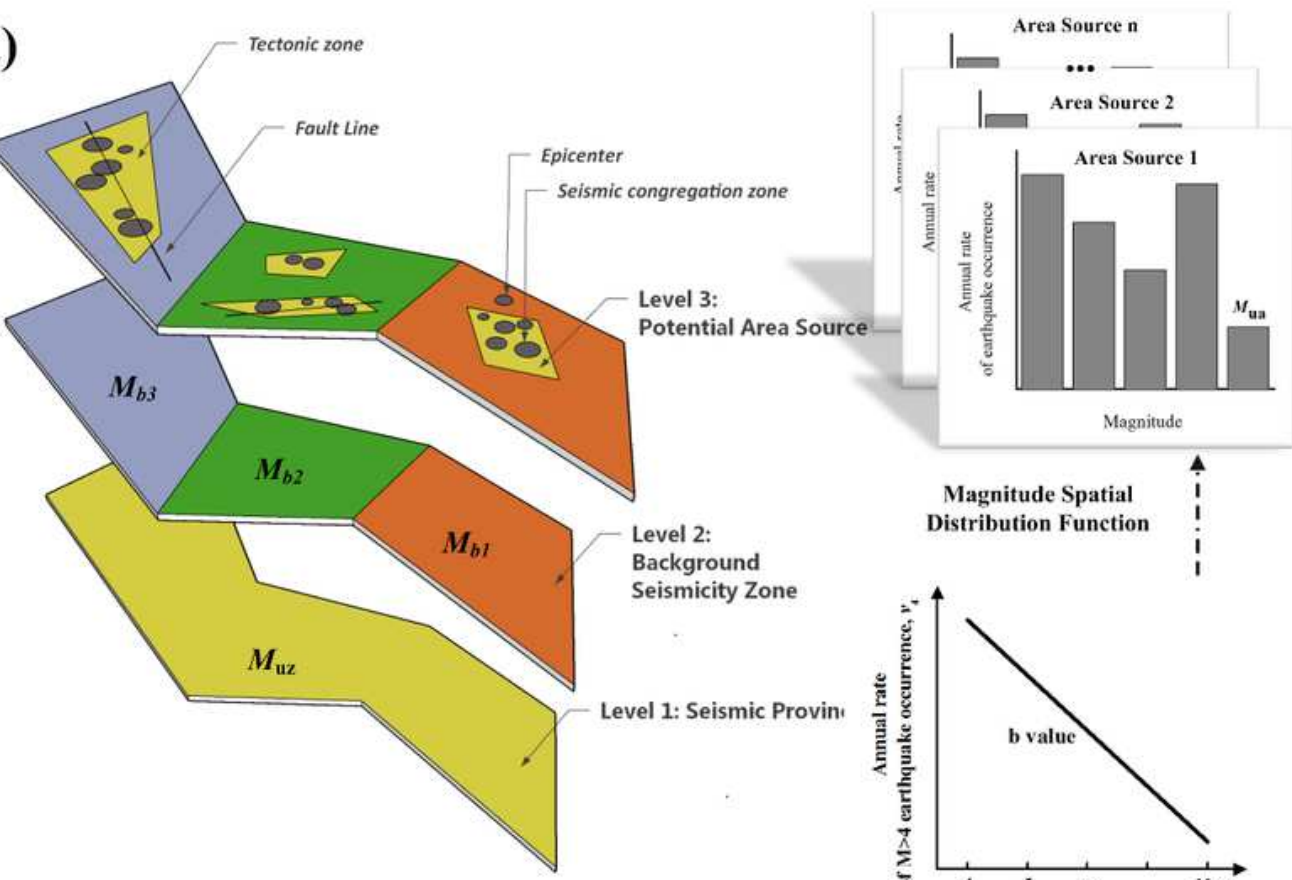

(b)

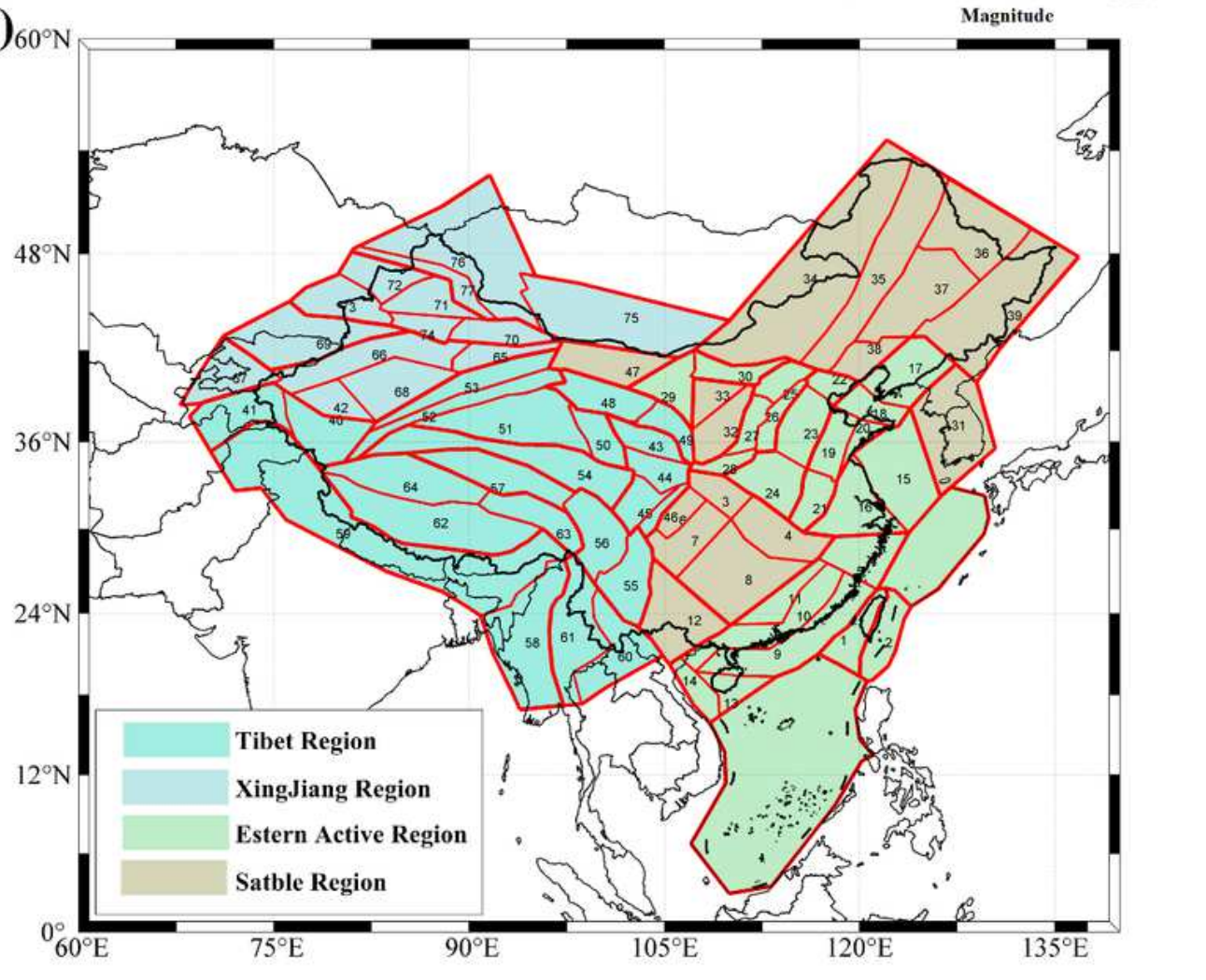

Figure 1

Tri-level seismic source model including the seismic province, background seismicity zone, and tectonic features zone (left). The seismicity of the seismic province has nonuniform distribution and is assigned between different potential source areas using the magnitude spatial function, while the distribution of 
seismicity is uniform within the potential source areas (right). (b) Spatial distribution of the 29 seismic provinces and 77 background seismicity zones. The different colors represent the four GMMs applied in four different regions. Note: The designations employed and the presentation of the material on this map do not imply the expression of any opinion whatsoever on the part of Research Square concerning the legal status of any country, territory, city or area or of its authorities, or concerning the delimitation of its frontiers or boundaries. This map has been provided by the authors.

(a)
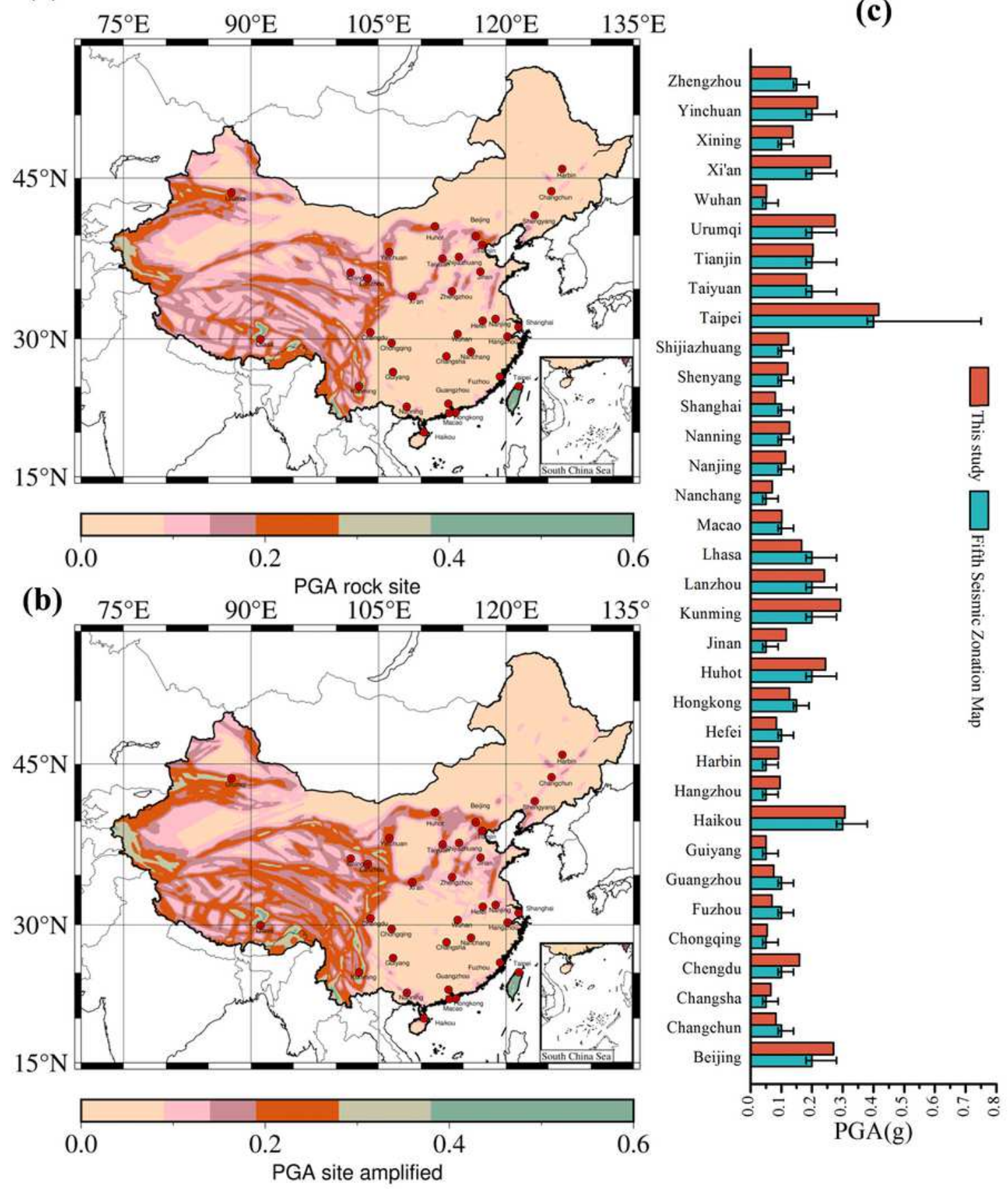

Figure 2 
Computed seismic hazard maps for mainland China: (a) 475-year MRP PGA for rock site condition (VS30 $=500 \mathrm{~m} / \mathrm{s}$ ), and (b) site-amplified PGA for CL-II sites. (c) Comparison of PGA values from our calculated hazard maps (orange bars, referring to Chinese soil site Class II) and from the fifth-generation map for major cities (blue bars). Range of PGA bins for the fifth-generation map is illustrated using error bars. Note: The designations employed and the presentation of the material on this map do not imply the expression of any opinion whatsoever on the part of Research Square concerning the legal status of any country, territory, city or area or of its authorities, or concerning the delimitation of its frontiers or boundaries. This map has been provided by the authors. 
(a)

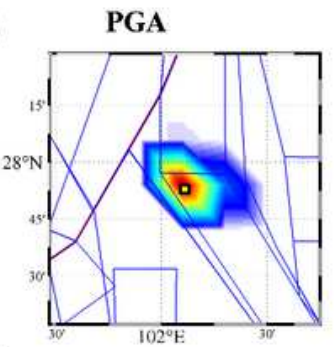

(b)

(c)
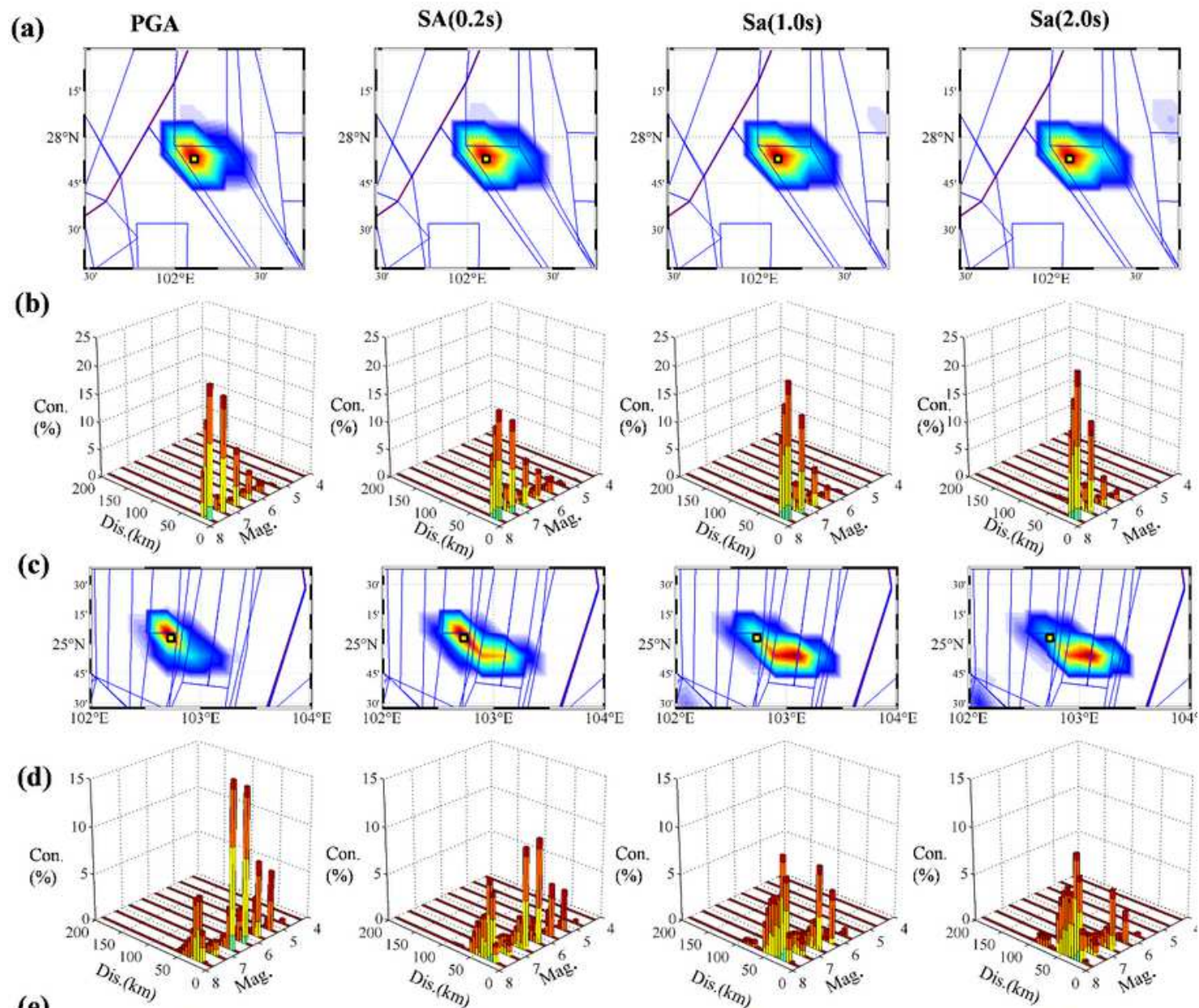

(e)

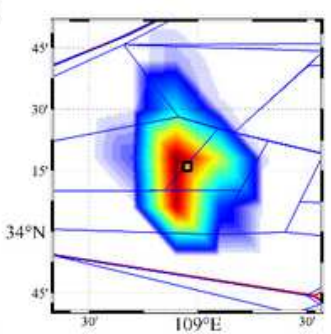

(f)
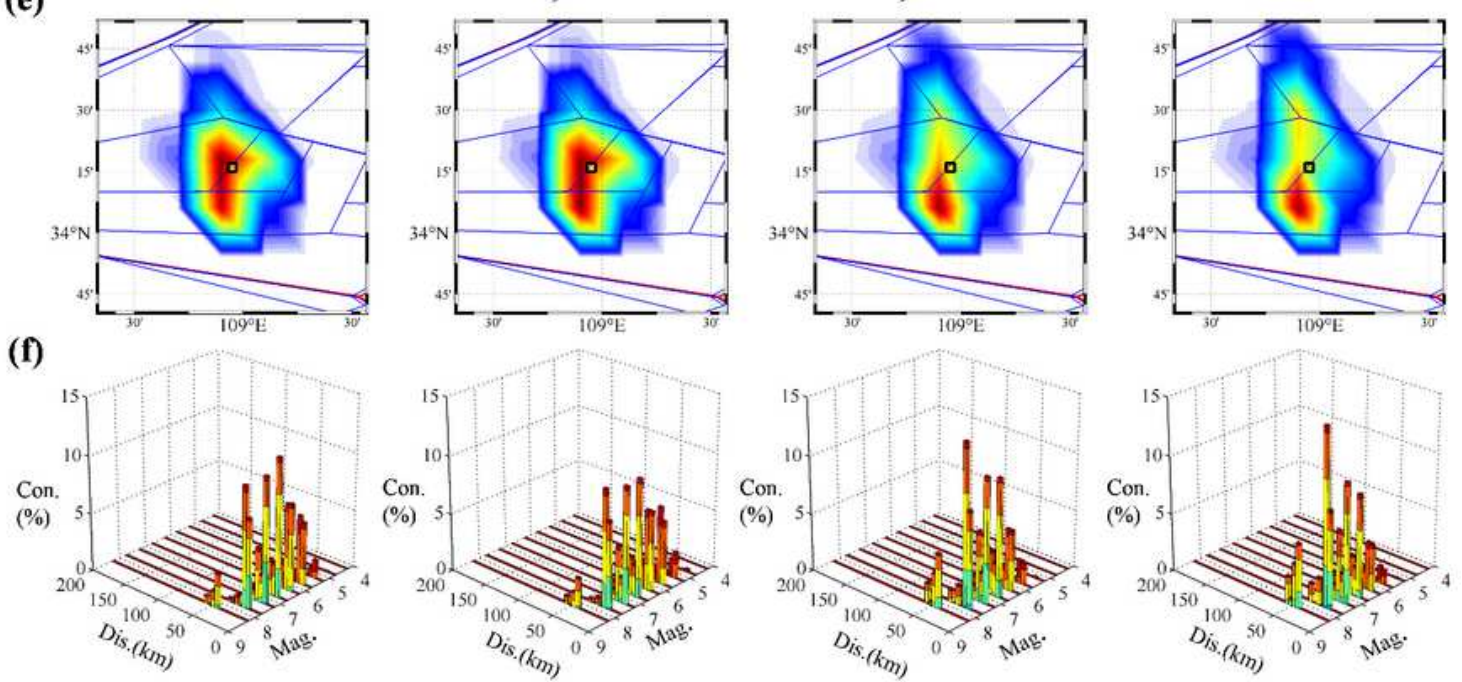

E bins: $\square[-3,-2] \square[-2,-1] \square[-1,0] \square[0,1] \square[1,2] \square[2,3]$

\section{Figure 3}

Contributions to hazard with MRP of 475 years for example cities, disaggregated in terms of latitudelongitude and joint $\mathrm{M}-\mathrm{R}-\varepsilon$ distribution regarding PGA, Sa (0.2 s), Sa (1.0 s), and Sa (2.0 s). The studied cities are (a) and (b) Xichang, (c) and (d) Kunming, and (e) and (f) Xi'an. 

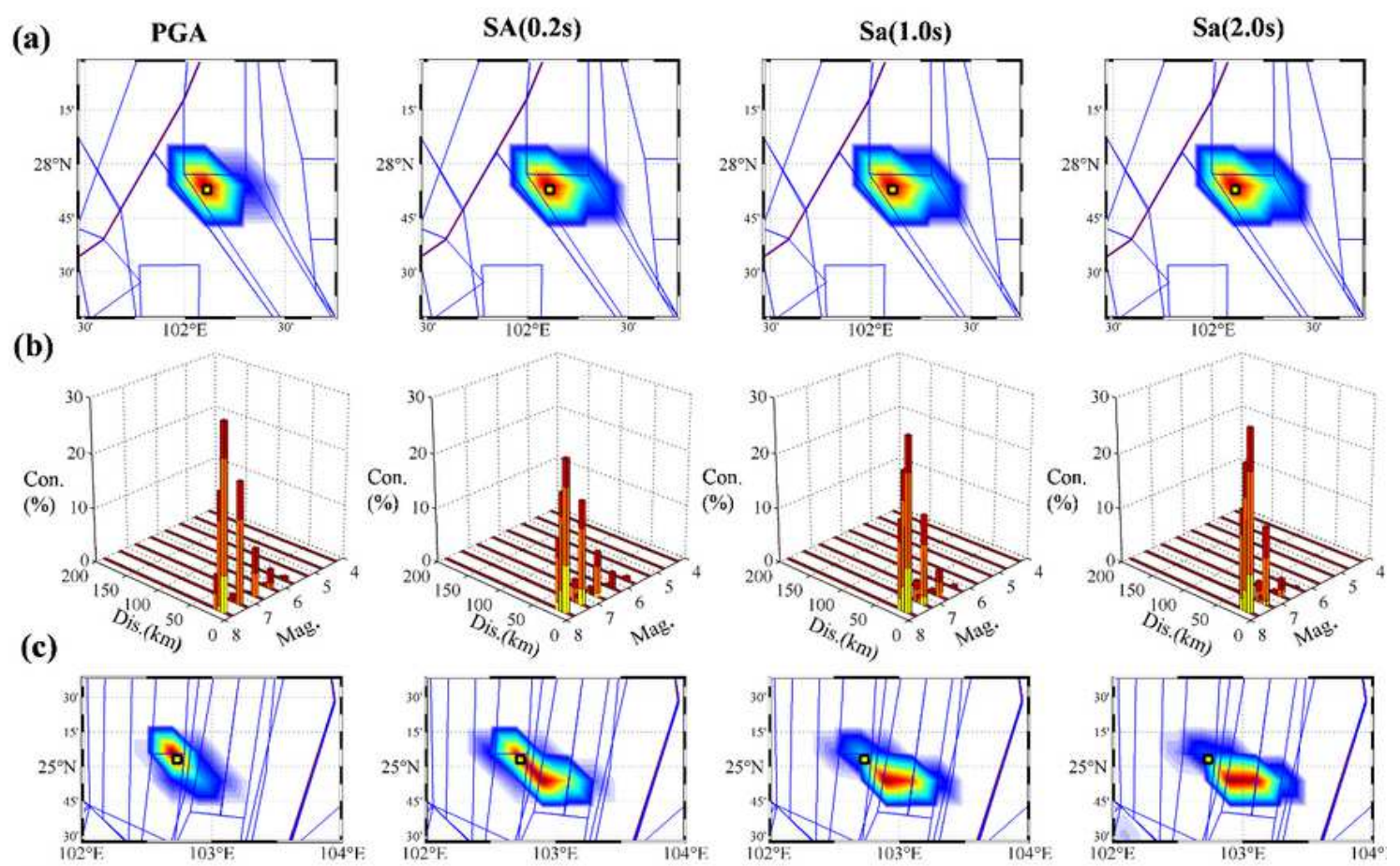

(d)
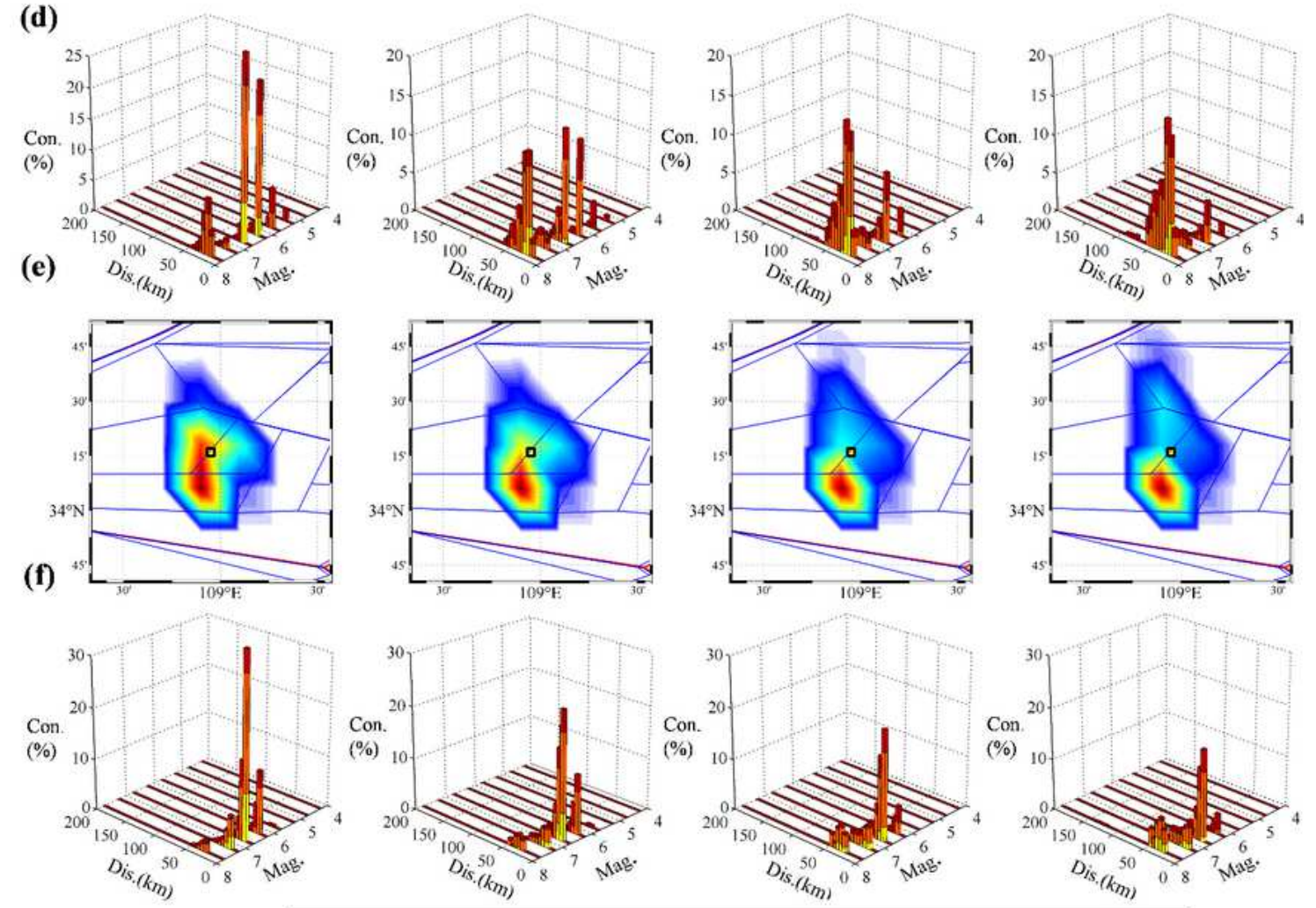

$\varepsilon$ bins:

$[-3,-2]$

$\square[-1,0] \square[0,1] \square[1,2]$

$[2,3]$

\section{Figure 4}

Contributions to hazard with MRP of 2475 years for example cities, disaggregated in terms of latitudelongitude and joint $\mathrm{M}-\mathrm{R}-\varepsilon$ distribution regarding PGA, Sa (0.2 s), Sa (1.0 s), and Sa (2.0 s). The studied cities are (a) and (b) Xichang, (c) and (d) Kunming, and (e) and (f) Xi'an. 
(a)
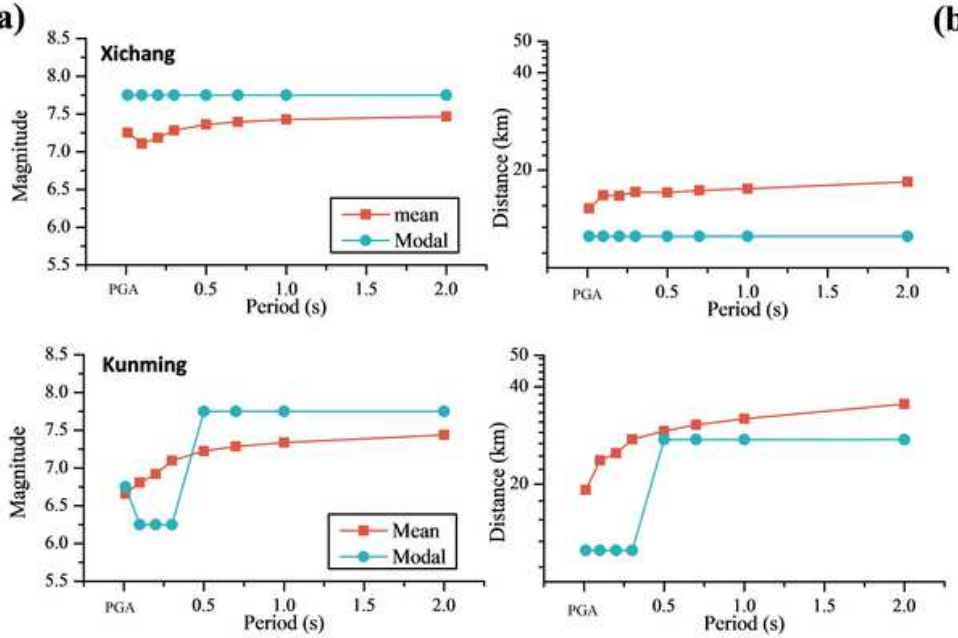

(b)
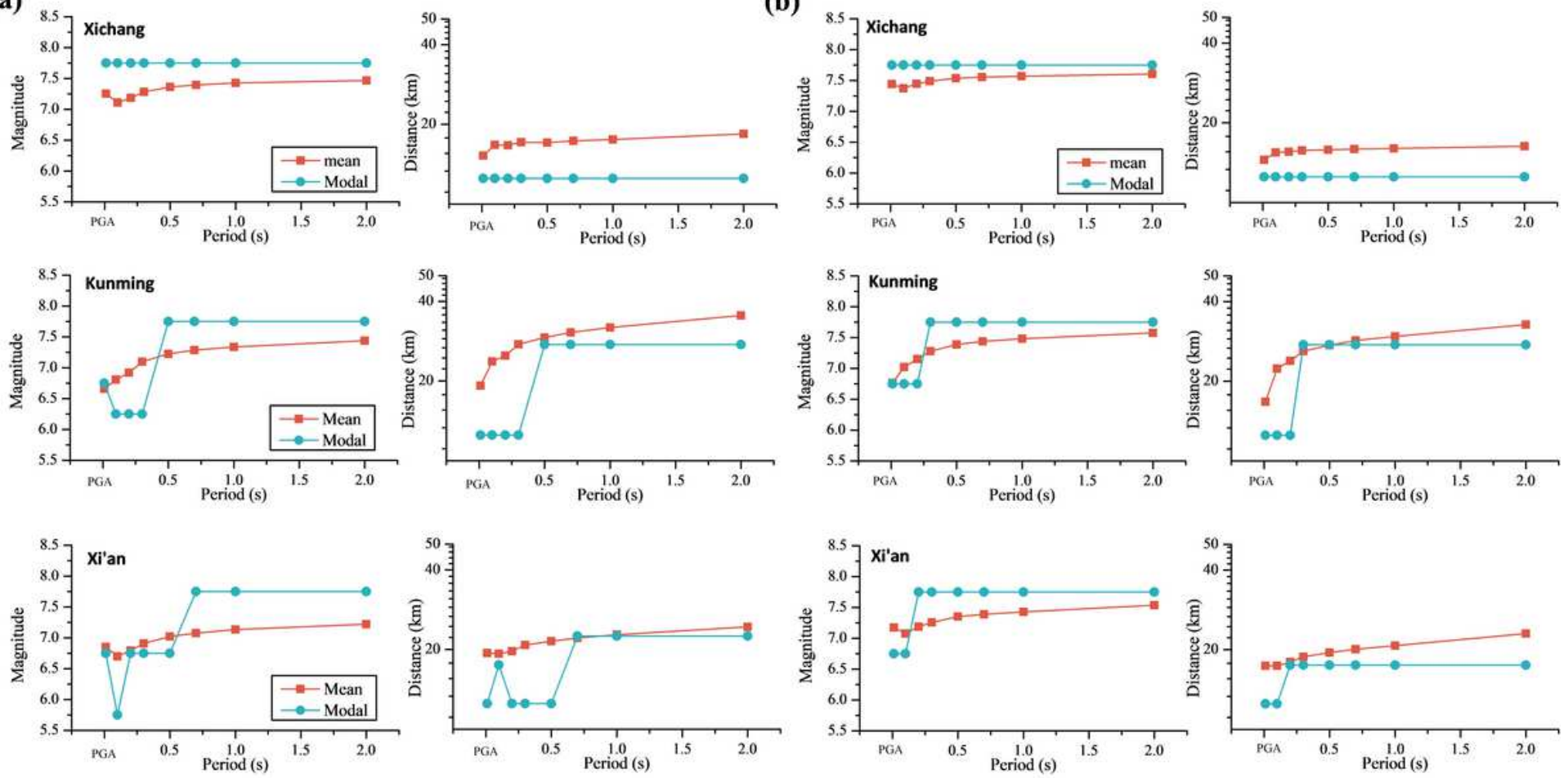

Figure 5

Variation of the mean and modal values of $\mathrm{M}$ and $\mathrm{R}$ with spectral period for Xichang, Kunming, and Xi'an: (a) 475-year MRP and (b) 2475-year MRP. 


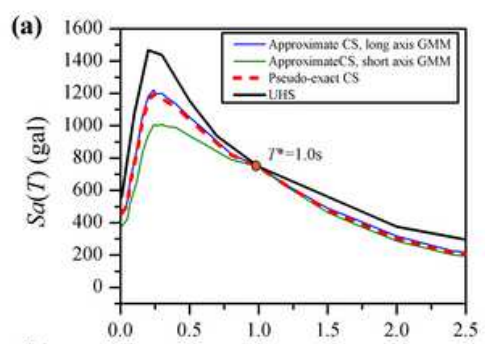

(b)
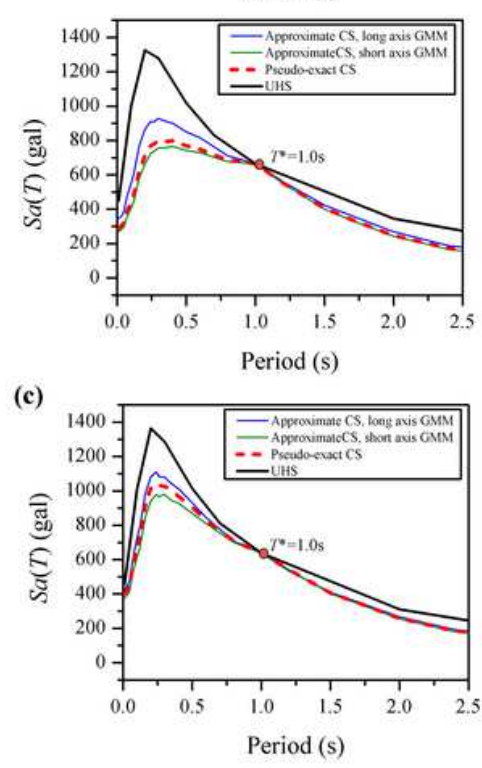

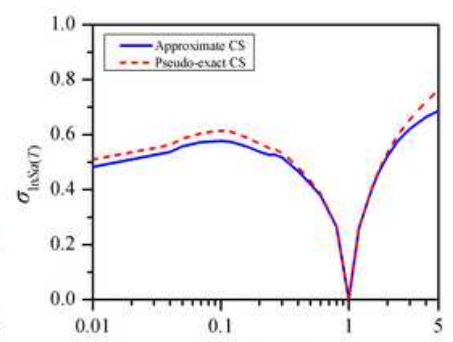

Period (s)
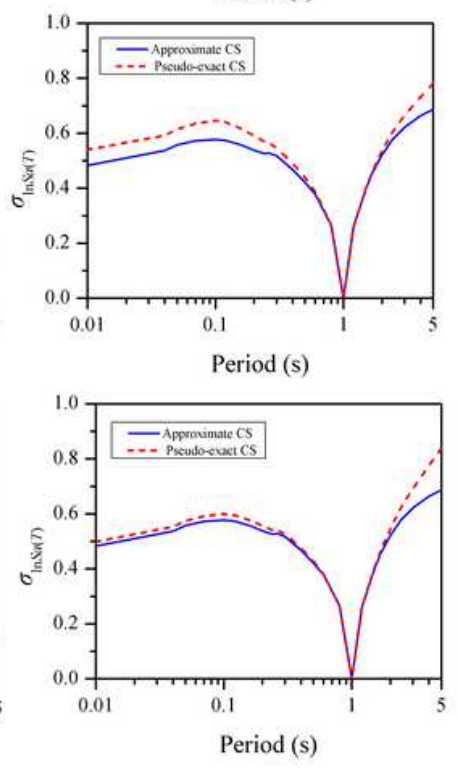
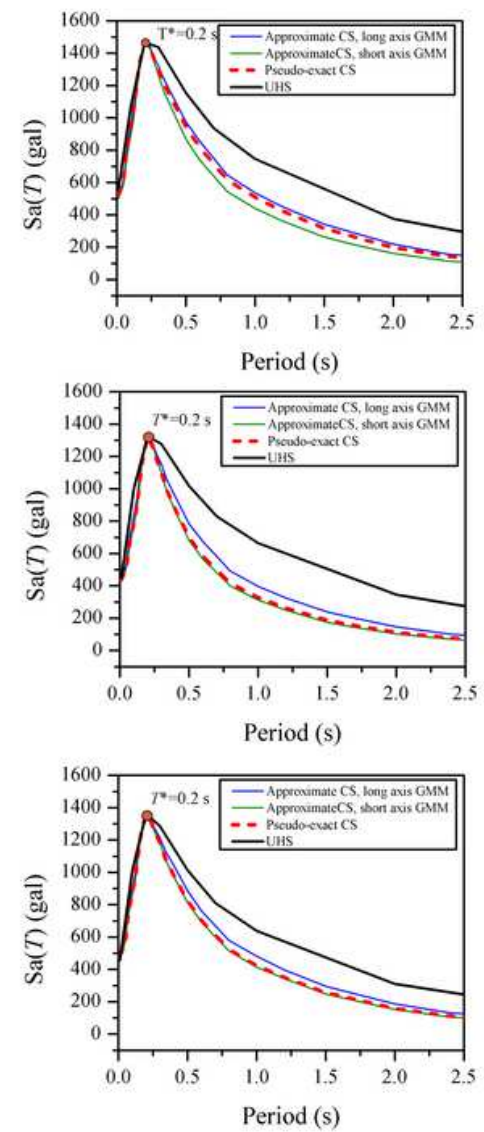
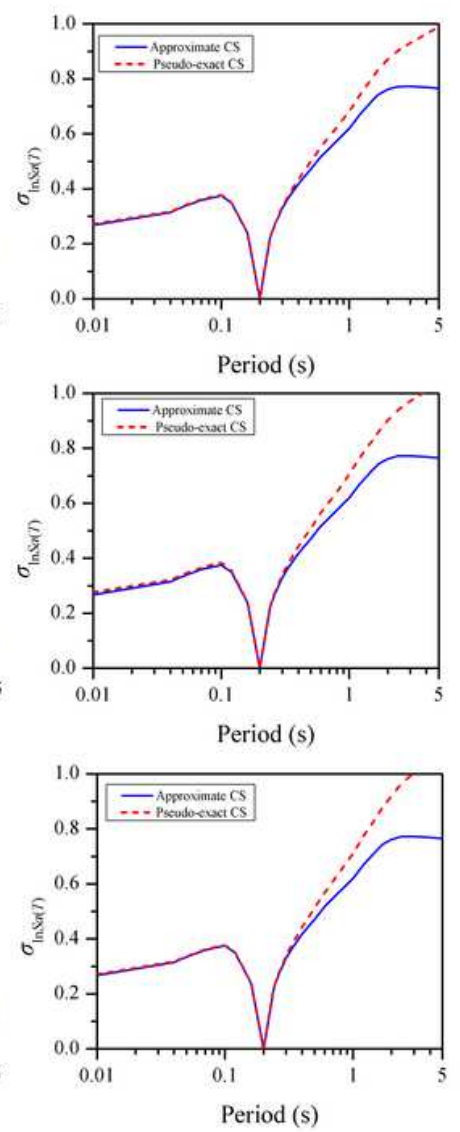

\section{Figure 6}

Mean conditional mean spectrum and conditional standard deviation for (a) Xichang, (b) Kunming, and (c) Xi'an city respectively regarding $\mathrm{Sa}\left(\mathrm{T}^{*}=0.2 \mathrm{~s}\right)$ and $\mathrm{Sa}\left(\mathrm{T}^{*}=1.0 \mathrm{~s}\right)$ with 2475 -yr MRP $(2 \%$ probability of exceedance in 50 years). The results were compared between: approximate CS using mean earthquake scenario and pseudo-exact CS derived from using the magnitude-longitude-latitude deaggregation results
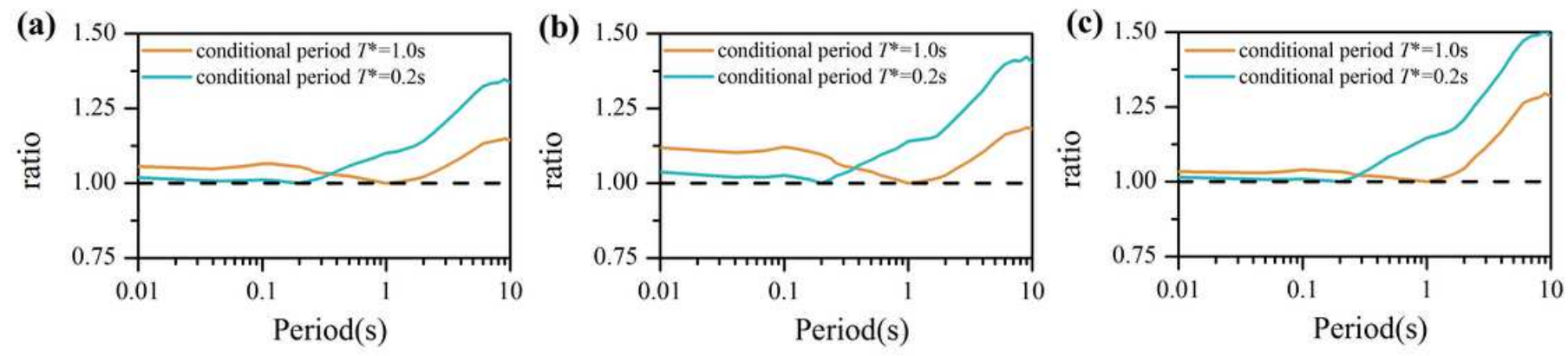

\section{Figure 7}

The ratio between the conditional standard deviation of pseudo-exact CS and approximate CS regarding (a) Xichang (b) Kunming, and (c) Xi'an city respectively. 

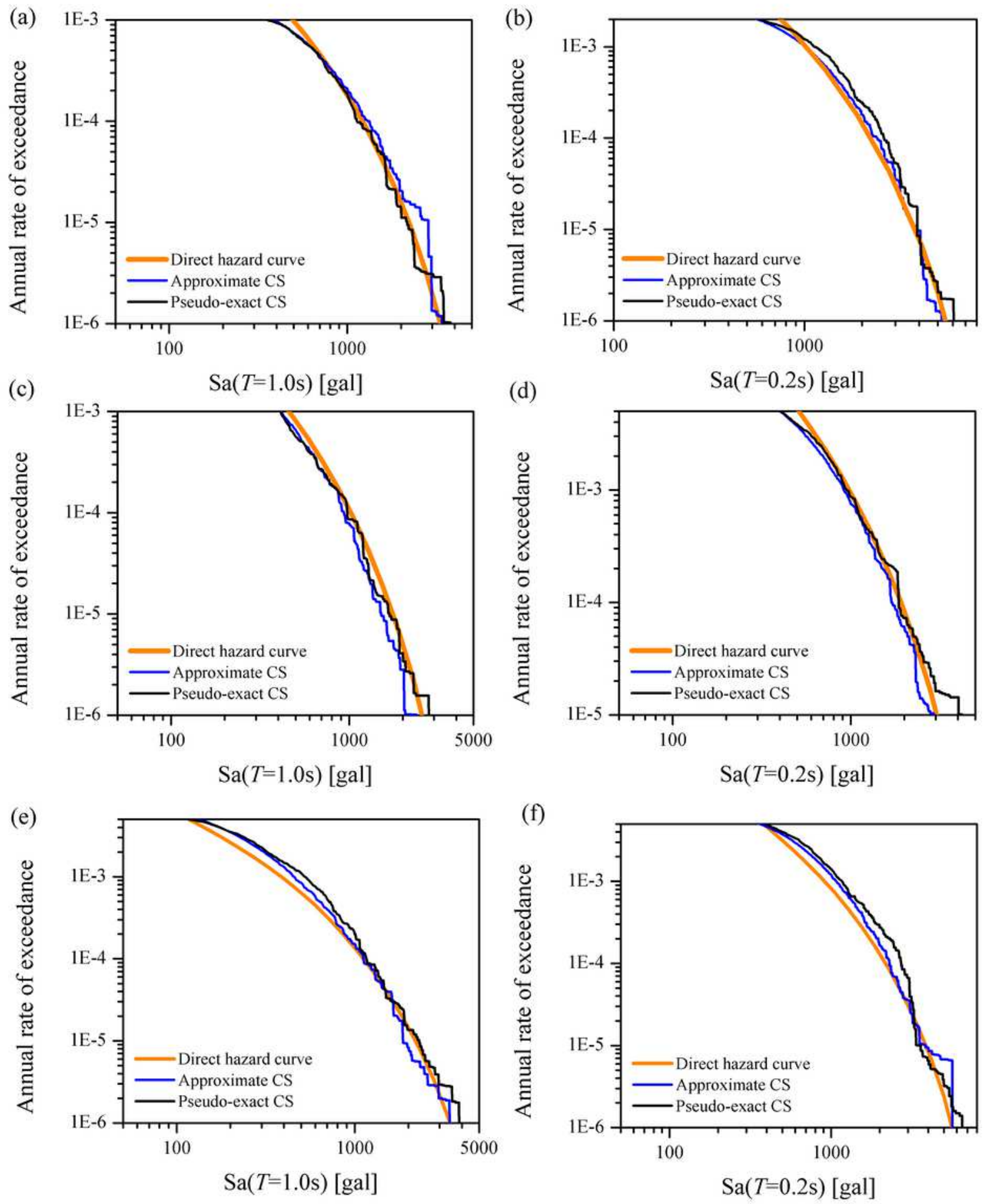

\section{Figure 8}

Comparsion between obtained annual exceedance rate versus corresponding hazard curves at conditional periods 1.0s and 0.2s. The results are compared for (a)(b) Xichang, (c)(d) Kunming City, and (e)(f) Xi'an City respectively. 